\title{
Impact of pulmonary exposure to gold core silver nanoparticles of different size and capping agents on cardiovascular injury
}

Nathan A. Holland', Leslie C. Thompson', Achini K. Vidanapathirana', Rahkee N. Urankarr', Robert M. Lust', Timothy R. Fennell ${ }^{2}$ and Christopher J. Wingard ${ }^{1 *}$

\begin{abstract}
Background: The uses of engineered nanomaterials have expanded in biomedical technology and consumer manufacturing. Furthermore, pulmonary exposure to various engineered nanomaterials has, likewise, demonstrated the ability to exacerbate cardiac ischemia reperfusion (I/R) injury. However, the influence of particle size or capping agent remains unclear. In an effort to address these influences we explored response to 2 different size gold core nanosilver particles (AgNP) with two different capping agents at 2 different time points. We hypothesized that a pulmonary exposure to AgNP induces cardiovascular toxicity influenced by inflammation and vascular dysfunction resulting in expansion of cardiac I/R Injury that is sensitive to particle size and the capping agent.
\end{abstract}

Methods: Male Sprague-Dawley rats were exposed to 200 mg of 20 or $110 \mathrm{~nm}$ polyvinylprryolidone (PVP) or citrate capped AgNP. One and 7 days following intratracheal instillation serum was analyzed for concentrations of selected cytokines; cardiac I/R injury and isolated coronary artery and aorta segment were assessed for constrictor responses and endothelial dependent relaxation and endothelial independent nitric oxide dependent relaxation.

Results: AgNP instillation resulted in modest increase in selected serum cytokines with elevations in IL-2, IL-18, and IL-6. Instillation resulted in a derangement of vascular responses to constrictors serotonin or phenylephrine, as well as endothelial dependent relaxations with acetylcholine or endothelial independent relaxations by sodium nitroprusside in a capping and size dependent manner. Exposure to both 20 and $110 \mathrm{~nm}$ AgNP resulted in exacerbation cardiac I/R injury 1 day following IT instillation independent of capping agent with $20 \mathrm{~nm}$ AgNP inducing marginally greater injury. Seven days following IT instillation the expansion of I/R injury persisted but the greatest injury was associated with exposure to $110 \mathrm{~nm}$ PVP capped AgNP resulted in nearly a two-fold larger infarct size compared to naïve.

Conclusions: Exposure to AgNP may result in vascular dysfunction, a potentially maladaptive sensitization of the immune system to respond to a secondary insult (e.g., cardiac I/R) which may drive expansion of I/R injury at 1 and 7 days following IT instillation where the extent of injury could be correlated with capping agents and AgNP size.

Keywords: Pulmonary Instillation, Myocardial Infarction, Coronary Artery, Aorta, Serum Cytokines, Nanotoxicology Abbreviations: 5-HT, Serotonin; ACh, Acetylcholine; AgNP, Nanosilver; Au-AgNP, Gold core silver nanoparticle; BAL, Bronchoalveolar lavage; BALF, Bronchoalveolar lavage fluid; BSA, Bovine serum albumin; CVD, Cardiovascular disease; $\mathrm{EC}_{50}$, Half maximal effective concentration; ENM, Engineered nanomaterial; G-CSF, Granulocyte colony stimulating factor; GM-CSF, Granulocyte macrophage colony stimulating factor; I/R, Ischemia/reperfusion; IL, Interleukin; IT, Intratracheal; LAD, Left anterior descending coronary artery; LPS, Lipopolysaccharide; MCP, Monocyte chemotactic (Continued on next page)

\footnotetext{
*Correspondence: wingardc@ecu.edu

${ }^{1}$ Department of Physiology, Brody School of Medicine at East Carolina

University, Greenville, NC 27834, USA

Full list of author information is available at the end of the article
} 


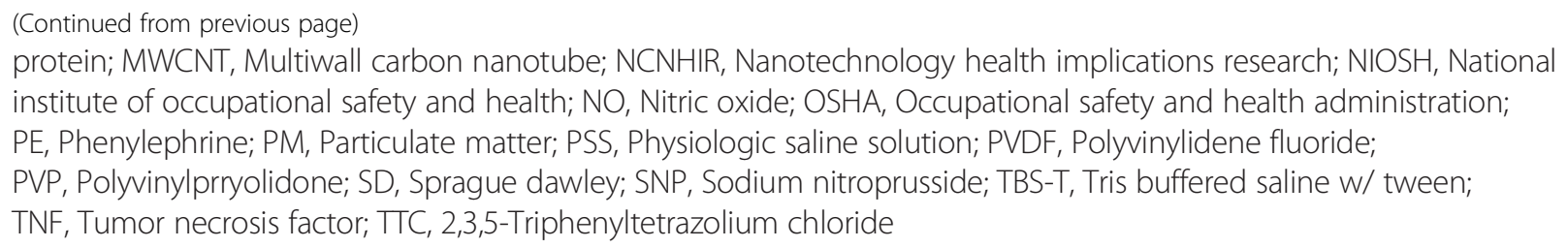

\section{Background}

The field of materials engineering has in recent decades yielded a new class of nano-sized materials. Engineered nanomaterials (ENM) are characterized by a size range of between $1 \mathrm{~nm}$ and $100 \mathrm{~nm}$ in at least one dimension, and a high surface to mass ratio $[1,2]$. The diverse physiochemical properties of ENM have been utilized in a multitude of industrial, commercial and consumer applications and have raised concerns over potential human or animal toxicity. One particular class ENM of great interest include the nano-silver (AgNP) species. Nano-silver particles have innate antimicrobial properties [3] and as a result have been utilized in biomedical applications: wound dressings, silver impregnated catheters, vascular prosthetics, surgical mesh $[4,5]$; and consumer applications: clothing and undergarments, air filters, laundry detergents, toiletries, and water taps [6]. The likelihood of human exposure has generated much interest in the potential toxicity of AgNP [7, 8]. Addressing concerns regarding the health impact of exposure to ENM the National Institute of Environmental Health Sciences Centers for Nanotechnology Health Implications Research (NCNHIR) Consortium was instituted to understand ENM's biological interactions. Pulmonary responses to ENMs have been a key focus regarding investigation routes $[2,9,10]$, and a large body of evidence describing AgNP and pulmonary interactions [11-15].

Despite the many investigations into the how pulmonary exposure to ENMs may impact pulmonary toxicity, there are far fewer investigations on the impact of pulmonary exposures and cardiovascular toxicity [16]. There is a strong relationship between pulmonary exposure to particulate matter and cardiovascular toxicity $[1,17-22]$. It has also been demonstrated that pulmonary exposure to other forms of ENMs are capable of inducing or exacerbating cardiovascular injury [23-26]. We have recently demonstrated that pulmonary exposure to $20 \mathrm{~nm}$ silver-core citrate capped AgNP is capable of inducing a systemic inflammatory response, coronary artery dysfunction, and expansion of cardiac ischemia/ reperfusion injury [27]. Despite these findings, the mechanisms which pulmonary exposure to AgNP may drive cardiovascular injury remain unknown. Recent studies have described toxicological responses associated with AgNP that may be strongly influenced by both particle size $[14,28]$ and capping agents [11, 29]. Understanding the interactions of AgNP capping as well as the influence of particle size on cardiovascular toxicity is an important, yet under investigated, step in understanding mechanisms of AgNP toxicity.

We hypothesize that intratracheal (IT) instillation of AgNP induces a systemic inflammatory response resulting in vascular dysfunction and expansion of cardiac I/R injury which is strongly dependent on particle size as well as capping agent. In order to test this hypothesis Male Sprague-Dawley (SD) rats were exposed to $200 \mu \mathrm{g}$ of either $20 \mathrm{~nm}$ or $110 \mathrm{~nm}$ gold core AgNP capped with either citrate or polyvinylprryolidione (PVP) by intratracheal instillation. One or 7 days following AgNP instillation serum was analyzed for changes in cytokines as a marker of inflammation, subjected to cardiac ischemia/reperfusion injury and small vessel myography, evaluating aortic and coronary artery reactivity.

\section{Methods \\ Animals}

Male Sprague-Dawley (SD) rats were purchased from Charles River Laboratory (Raleigh, NC, USA) at 51-54 days of age and weighed between 201-225 g. Rats were housed two per cage under a $12 \mathrm{~h}$ light/dark cycle. Standard rat chow and water were provided ad libidum. Animals were randomly assigned to the following experimental groups for 1 day or 7 days post-instillation analysis: Naïve, Citrate Vehicle, $20 \mathrm{~nm} \mathrm{Au-AgNp/Citrate,}$ $100 \mathrm{~nm}$ Au-AgNP/Citrate, polyvinylprryolidone (PVP) Vehicle, $20 \mathrm{Au}-\mathrm{AgNP} / \mathrm{PVP}$, and $110 \mathrm{~nm} \mathrm{Au-AgNP/PVP}$. Animals were allowed a 1 week acclimatization period in the East Carolina University Department of Comparative Medicine vivarium before beginning experimentation. East Carolina University's Institutional Animal Care and Use Committee approved all animal handling and experimental procedures.

\section{Nanomaterial and vehicles}

For the purposes of investigation both PVP and Citrate coated gold-core silver nanoparticles (AgNP) were used for instillation. The $20 \mathrm{~nm}$ and $110 \mathrm{~nm}$ AgNP were manufactured and provided to the investigators by nanoComposix (San Diego, CA) through the National Institute of Environmental Health Sciences Centers for 
Nanotechnology Health Implications Research (NCNHIR) Consortium funded through NIEHS. The prepared nanomaterials were independently characterized by the Nanotechnology Characterization Laboratory associated with the National Cancer Institute (Fredrick, MD) as well as independently characterized by consortium investigators $[12,30]$. A summary of the nanoparticle suspension characteristics can be found in Table 1. The vehicle for PVP control groups was created by adding sterile saline to a PVP dry powder (10 and $40 \mathrm{Kda}$, Sigma-Aldrich, St. Louis, MO) to yield a $1.4 \% \mathrm{PVP} / \mathrm{saline}$ solution. The vehicle control for citrate AgNP was created as a $2 \mathrm{mM}$ solution of sodium citrate (Sigma-Aldrich, St. Louis, MO) dissolved in deionized water.

\section{AgNP suspension preparation, dosing, and intratracheal instillation (IT)}

AgNP aliquots were cup-horn sonicated for $30 \mathrm{~s}$ at $65 \%$ amplitude (Misonix Model 1510r-MTH, Branson Ultrasonics Corp. Danbury, CT). Silver nanoparticle and vehicle aliquots were vortexed for $30 \mathrm{~s}$ immediately prior to instillation. Rats were anesthetized by inhalation of a 50:50 isoflurane propylene-glycol mixture in an induction chamber. After establishment of deep anesthesia as assessed by lack of hind limb withdrawal from a toe pinch, the rat was suspended by the frontal incisors on an inclined board. The tongue was withdrawn from the oral cavity and anteriorly displaced using padded forceps and a $200 \mu \mathrm{L}$ pipette tip containing the AgNP suspension was placed into the laryngopharynx, just superior to the glottis. Two hundred microliters of AgNP suspension containing $200 \mu \mathrm{g}$ of AgNP or vehicle was dispensed into the glottal opening and the rat was stimulated to inhale while securing the tongue with forceps, ensuring pulmonary aspiration. The dose selected was set as a proof of concept dose agreed upon by the NCNHIR consortium members for AgNP in vivo toxicity and at this dosing could induce potential toxicological effects but not mortality or morbidity to the animal, and represents approximately 720 times the permissible exposure limit to all forms of silver at
$0.01 \mathrm{mg} / \mathrm{m}^{3}$ for an $8 \mathrm{~h}$ work day as established by NIOSH and OSHA [31] based on rat minute ventilation rate and alveolar surface area [32]. Following instillation the rats were returned to their home cage and monitored until they resumed normal grooming behavior.

\section{Bronchoalveolar lavage, cell differential, and protein quantification}

Sprague Dawley rats were euthanized and bronchoalveolar lavage (BAL) was performed employing a modified procedure as described by Katwa et al. [33]. Rats were anesthetized with isoflurane and euthanized by pneumothorax. The left main bronchus was ligated and a tracheotomy was performed. A 14 gauge angiocatheter was inserted into the trachea and secured with $2-0$ suture. A bolus of Hanks balanced saline solution $(23.1 \mathrm{ml} / \mathrm{kg})$ was lavaged into the right lung three times successively. Recovered BAL fluid was centrifuged at $1000 \times \mathrm{g}$ for $10 \mathrm{~min}$ at $4{ }^{\circ} \mathrm{C}$. Cell pellets were suspended in $1 \mathrm{~mL}$ of cold Hanks balanced saline solution. Total cell counts were determined with a Cellometer Auto $\times 4$ (Nexcelom Biosciences, LLC, Lawrence, MA). BAL fluid volumes containing 20,000 cells were centrifuged onto glass slides using a Cytospin III (Shandon Scientific Ltd, Cheshire, UK) and stained with three-step hematology stain (Richard Allan Scientific, Kalamazoo, MI). Cell differentials were determined by microscopy counting 300 cells per slide to estimate percentage of recovered cell types. BAL supernatant was used for protein quantification using a standard Bradford protein assay. Samples were plated in duplicate using a 96-well plate. Absorbance values were read at $562 \mathrm{~nm}$ using a BIO-TEK Synergy HT plate reader (BIO-TEK, Winooski, VT) and data were analyzed with Gen5 software (BIO-TEK, Winooski, VT).

\section{Serum collection}

Following anesthesia by isoflurane inhalation a cardiac puncture of the right ventricle at time of animal sacrifice was performed. Serum was separated from whole blood sample as previously described [23].

Table 1 Characterization of Au-AgNP suspensions

\begin{tabular}{|c|c|c|c|c|}
\hline & \multicolumn{2}{|c|}{ Citrate Capped AgNP } & \multicolumn{2}{|c|}{ PVP Capped AgNP } \\
\hline & $20 \mathrm{~nm}$ & $110 \mathrm{~nm}$ & $20 \mathrm{~nm}$ & $110 \mathrm{~nm}$ \\
\hline Hydrodynamic Size (nm) & $24.00 \pm 0.05$ & $104.20 \pm 0.12$ & $26.00 \pm 0.09$ & $112.30 \pm 0.15$ \\
\hline Core Diameter (nm) & $20.28 \pm 0.23$ & $111.3 \pm 2.0$ & $20.95 \pm 0.31$ & $114.2 \pm 1.4$ \\
\hline Zeta Potential (mV) & $-48.50 \pm 2.06$ & $-43.02 \pm 1.47$ & $-37.12 \pm 1.14$ & $-25.92 \pm 1.24$ \\
\hline Silver Concentration $(\mathrm{mg} / \mathrm{g})$ & $1.105 \pm 0.007$ & $0.980 \pm 0.014$ & $1.090 \pm 0.001$ & $1.101 \pm 0.003$ \\
\hline Endotoxin Concentration (EU/mL) & $<0.5 \pm 0$ & $<0.5 \pm 0$ & $1.133 \pm .291$ & $<0.5 \pm 0$ \\
\hline
\end{tabular}

Particle characterization data for citrate and PVP capped AgNP. Hydrodynamic size reported was determined by DLS and reported as Z-average. Core diameter was determined from TEM and Silver concentration by ICP-MS. As reported form The Nanotechnology Characterization Laboratory (NCL, Fredrick, MD) Data are as presented as a mean \pm SEM of 6 separate aliquots 


\section{Quantification of serum cytokines}

Serum concentrations of IL-1 $\beta$, IL-2, IL-5, IL-6, IL-10, IL-13, IL-18, MCP-1, G-CSF, GM-CSF, IFN $\gamma$, MCP-1, MIP- $1 \alpha$, RANTES, and TNF $\alpha$ were measured at selected time points utilizing a Milliplex MAP Cytokine/Chemokine Panel (EMD Millipore, Billerica, MA) according to the manufacturer's instructions. Serum samples from the PVP capped AgNP and respective vehicle group were run on a Luminex 200 (Luminex, Austin, TX), while serum samples from Citrate capped AgNP and vehicle group were run on a MagPix system (Luminex, Austin, TX). All results were reported and analyzed using the Milliplex Analyst software (vVersion 5.1, EMD Millipore, Billerica, MA).

\section{Lung and heart protein oxidation}

Heart and lavaged lung tissue was homogenized in a RIPA Buffer with $50 \mathrm{mM}$ DTT and Halt ${ }^{\text {Tw }}$ Protease Inhibitor (Thermo Fisher Scientific, Waltham, MA). Protein concentration was determined with a Bradford Protein Assay (Bio-Rad Laboratories, Hercules, CA). Determination of protein oxidation was performed utilizing an OxyBlot $^{\text {tix }}$ (EMD Millipore, Billerica, MA) according to manufacturer's instruction. Following derivatization, between 10-15 $\mu \mathrm{g}$ protein from each sample were loaded onto a Criterion Stain-Free Gel (Bio-Rad Laboratories, Hercules, CA) and electrophoresed at $200 \mathrm{~V}$ for $60 \mathrm{~min}$. Gels were activated for $45 \mathrm{~s}$ with UV light using a ChemiDoc ${ }^{\text {mi }}$ Touch (Bio-Rad Laboratories, Hercules, CA). Proteins were transferred utilizing a tank transfer with Towbin's Buffer at $100 \mathrm{~V}$ for $60 \mathrm{~min}$ on to low fluorescence PVDF membranes (EMD Millipore, Billerica, MA). Membrane was imaged with a ChemiDoc ${ }^{\mathrm{mat}}$ following transfer to detect and quantify total protein. The membrane was then blocked in $1 \%$ BSA/TBS-T for $60 \mathrm{~min}$ followed by incubated, at room temperature, with $1^{\circ}$ antibody (1:150) for $60 \mathrm{~min}$. The membrane was then washed with TBS-T and incubated with $2^{\circ}$ antibody (1:300) for $1 \mathrm{~h}$. The membrane was then washed with TBS-T and then incubated for $5 \mathrm{~min}$ in SuperSignal $^{\mathrm{m}}{ }^{\mathrm{T}}$ West Pico Chemiluminescent Substrate (Thermo Fisher Scientific, Waltham, MA). The membrane was imaged on a ChemiDoc ${ }^{\mathrm{Tw}}$ and analyzed with Image Lab $^{\text {tw }} 5.2$ (Bio-Rad Laboratories, Hercules, CA). For determination of protein oxidation analyzed density of nonderivative control lanes were subtracted from derivitized lanes, and all lanes were normalized to total protein.

\section{Coronary artery isolation and pharmacology}

Coronary artery isolation and aorta vessel segment pharmacological response assessments were performed 1 or 7 days following IT exposure to AgNP or vehicle from animals not subject to cardiac I/R injury protocol. Isolation of the coronary artery was performed as previously described [23]. The heart and thoracic aorta was excised and placed in ice-cold physiological saline solution (PSS); $[\mathrm{mM}] 140.0 \mathrm{NaCl}, 5.0 \mathrm{KCl}, 1.6 \mathrm{CaCl}_{2}, 1.2$ $\mathrm{MgSO}_{4}, 1.2$ 3-[N-morpholino]-propane sulfonic acid, 5.6 D-glucose, and 0.02 EDTA (pH 7.4@ $\left.37{ }^{\circ} \mathrm{C}\right)$. Pairs of $\sim 2 \mathrm{~mm}$ segments of the left anterior descending coronary artery (LAD) and aorta were excised and mounted into chambers of a $610 \mathrm{M}$ multichannel myograph (DMT, Ann Arbor, MI). Coronary artery segment lumen diameter was adjusted so that resting tension was $90 \%$ of the wall tension at $13.3 \mathrm{kPa}$ while the passive force of $20 \mathrm{mN}$ established for aorta segments. Tissue viability was assessed with a potassium depolarization using $109 \mathrm{mM} \mathrm{K}{ }^{+} \mathrm{PSS}$ $\left(\mathrm{Na}^{+}\right.$substituted with $\mathrm{K}^{+}$in an equal molar fashion). Stress generation of greater than $1 \mathrm{mN} / \mathrm{mm}^{2}$ following $\mathrm{K}^{+} \mathrm{PSS}$ stimulation was considered adequate for vessel viability. Vessel segments were subsequently washed with PSS and endothelial integrity was assessed using a $1 \mu \mathrm{M}$ serotonin (5-HT) or phenylephrine (PE) stimulation followed by $3 \mu \mathrm{M}$ acetylcholine (ACh). An ACh relaxation response of $>50 \%$ loss of the agonist stress was considered acceptable endothelial integrity. Segments were washed every $10 \mathrm{~min}$ with fresh PSS for a minimum of 3 times and then subject cumulative doseresponse assessments [23,34]. Paired segments were subjected to cumulative concentrations of 5-HT (10 $\mathrm{nM}-3 \mu \mathrm{M})$ or PE $(1 \mathrm{nM}-10 \mu \mathrm{M})$. The active stress $\left(\mathrm{mN} / \mathrm{mm}^{2}\right)$ generated in response to stimulation of paired segments was averaged at each concentration for data reporting. Upon establishing stable tension after addition of the highest agonist concentration, one of the paired segments was subject to endothelialdependent relaxation with addition of increasing concentrations of $\mathrm{ACh}(1 \mathrm{nM}-1 \mu \mathrm{M})$ and the other segment was subjected to endothelial-independent relaxation with addition of increasing concentrations of sodium nitroprusside (SNP, $1 \mathrm{nM}-1 \mu \mathrm{M}$ ).

\section{Cardiac ischemia/reperfusion}

One or 7 days following AgNP or vehicle intratracheal (IT) instillation rats were anesthetized with an intramuscular injection of ketamine/xylazine $(90 / 10 \mathrm{mg} / \mathrm{kg}$, respectively) and subject to a cardiac ischemia/reperfusion (I/R) injury [24, 27]. Anesthesia was maintained throughout the procedure with supplemental injections of ketamine/xylazine. Body temperature was maintained at $37^{\circ} \mathrm{C}$ with a heating pad and TC-1000 Temperature Controller (CWE, Inc., Ardmore, PA). Once an adequate plane of anesthesia was achieved, as assessed by lack of hind limb withdrawal from a toe pinch, the rats were intubated via tracheostomy with a 16 gauge angiocatheter. Rats were then ventilated with $100 \%$ oxygen via an Inspira Advanced Safety Ventilator (Harvard Apparatus, Holliston, MA) with setting of $3 \mathrm{~mL}$ tidal volume at 81 
breaths per minute. Following a left parasternal thoracotomy, a temporary ligature of 6-0 vicryl suture was placed around the left anterior descending (LAD) coronary artery to induce $20 \mathrm{~min}$ of ischemia and removed to allow reperfusion as previously described [24].

\section{Quantification of infarct size}

Following the ischemia reperfusion protocol the vena cava was severed and the descending thoracic aorta was cannulated with polyethelene 90 and advanced to the coronary ostia. The heart was retrograde perfused with $5 \mathrm{~mL} 0.09 \%$ saline solution followed by $5 \mathrm{~mL}$ of $0.25 \%$ TTC (Sigma-Aldrich, St. Louis, MO) to determine viable from infarcted tissue [35]. Following infusion of TTC the LAD was re-occluded and the heart infused with $1 \%$ Evans blue dye for demarcation of remote myocardium (i.e., myocardium not subjected to the induced ischemic injury). Following Evans blue infusion, the heart was excised and sliced into approximate $1 \mathrm{~mm}$ thick sections distal to the occlusion. The slices were gently sandwiched between two glass slides and both sides and digitally photographed. Image J (National Institutes of Health) was used to quantify the area of the left ventricle, area at risk, and area of infarction.

\section{Statistical analysis}

All data are presented as mean value \pm SEM. A $p$-value of $<0.05$ indicates statistical significance unless otherwise noted. GraphPad Prism software (Version 6, LaJolla, CA) was used for the purposes of statistical analysis and graphing. Coronary artery vascular response curves were generated using nonlinear regression analysis of the f-pair parameter best-fit values.
Curves were compared using ANOVA with Tukey's post-test for multiple comparisons. Calculated $\mathrm{EC}_{50}$ and Hill slope values were generated by averaging the normalized concentration-response curves (0-100 \%) of individual subjects within a cohort. Results were compared using ANOVA and Tukey's post-test for multiple comparisons. Differences between time and particle capping were performed by $t$-test. Group size was calculated based on power analysis of cardiac $I / R$ experiments.

\section{Results}

Broncheolar alveolar lavage cell differentials and protein quantification

Summary of the bronchiolar alveolar lavage (BAL) data can be found in Table 2. One day following instillation of $20 \mathrm{~nm}$ of $110 \mathrm{~nm}$ citrate capped AgNP the total percentage of BAL macrophages was significantly smaller compared to the citrate control. Concurrently, a larger number of recovered epithelial cells was observed for both $20 \mathrm{~nm}$ of $110 \mathrm{~nm}$ citrate capped AgNP. There were no differences in percentage of neutrophils, eosinophils, or lymphocytes 1 day following exposure to $20 \mathrm{~nm}$ of $110 \mathrm{~nm}$ citrate capped AgNP. Additionally, there was no difference in BAL total protein concentration following instillation of citrate vehicle or citrate capped AgNP.

The instillation of $20 \mathrm{~nm}$ or $110 \mathrm{~nm}$ PVP capped AgNP also resulted in a smaller percentage of BAL macrophages compared to vehicle control, with an increased number of BAL epithelial cells. Instillation of $20 \mathrm{~nm}$ and $110 \mathrm{~nm}$ PVP capped AgNP resulted in increased BAL protein concentration 1 day following exposure with no

Table 2 Lung BAL cell differentials and protein

\begin{tabular}{|c|c|c|c|c|c|c|}
\hline & $\%$ Macrophages & $\%$ Neutrophils & \% Eosinophils & \% Lymphocytes & \% Epithelial Cells & Protein $(\mathrm{mg} / \mathrm{mL})$ \\
\hline \multicolumn{7}{|l|}{1 Day } \\
\hline Citrate & $96.0 \pm 0.7$ & $0.1 \pm 0.1$ & $0.1 \pm 0.1$ & $0.1 \pm 0.1$ & $3.8 \pm 0.7$ & $0.2 \pm 0.1$ \\
\hline $20 \mathrm{~nm}$ AgNP & $91.8 \pm 1.2^{b}$ & $1.4 \pm 1.3$ & $0.4 \pm 0.3$ & $1.1 \pm 0.3$ & $5.3 \pm 0.5$ & $0.4 \pm 0.1$ \\
\hline $110 \mathrm{~nm}$ AgNP & $91.1 \pm 0.5^{b}$ & $0.6 \pm 0.6$ & $0.8 \pm 0.4$ & $0.3 \pm 0.1$ & $7.0 \pm 0.3^{b}$ & $0.4 \pm 0.0$ \\
\hline PVP & $95.2 \pm 0.9$ & $0.1 \pm 0.1$ & $0.4 \pm 0.3$ & $0.8 \pm 0.6$ & $3.5 \pm 0.5$ & $0.6 \pm 0.1$ \\
\hline $20 \mathrm{~nm}$ AgNP & $92.3 \pm 0.9^{b}$ & $0.6 \pm 0.1$ & $0.3 \pm 0.2$ & $0.3 \pm 0.2$ & $6.4 \pm 1.0$ & $0.8 \pm 0.1^{b}$ \\
\hline $110 \mathrm{~nm}$ AgNP & $91.9 \pm 0.8^{b}$ & $0.0 \pm 0.0$ & $0.4 \pm 0.4$ & $0.7 \pm 0.2$ & $7.0 \pm 0.9$ & $0.8 \pm 0.1^{b}$ \\
\hline \multicolumn{7}{|l|}{7 Day } \\
\hline Citrate & $88.8 \pm 4.7$ & $0.4 \pm 0.2$ & $0.1 \pm 0.1$ & $1.1 \pm 0.6$ & $9.6 \pm 4.3$ & $0.2 \pm 0.0$ \\
\hline $20 \mathrm{~nm}$ AgNP & $96.9 \pm 0.9^{b}$ & $1.3 \pm 1.0$ & $0.2 \pm 0.2$ & $0.9 \pm 0.4$ & $0.7 \pm 0.1^{b}$ & $0.3 \pm 0.2$ \\
\hline $110 \mathrm{~nm}$ AgNP & $96.8 \pm 1.4^{b}$ & $0.6 \pm 0.3$ & $0.1 \pm 0.1$ & $2.0 \pm 0.9$ & $0.5 \pm 0.3^{b}$ & $0.2 \pm 0.1$ \\
\hline PVP & $95.3 \pm 1.0$ & $0.6 \pm 0.3$ & $0.1 \pm 0.1$ & $1.5 \pm 0.6$ & $2.5 \pm 1.1$ & $0.2 \pm 0.0$ \\
\hline $20 \mathrm{~nm}$ AgNP & $90.7 \pm 3.9$ & $3.6 \pm 2.7$ & $0.2 \pm 0.2$ & $3.1 \pm 2.3$ & $2.5 \pm 0.9$ & $0.2 \pm 0.0$ \\
\hline $110 \mathrm{~nm}$ AgNP & $94.2 \pm 1.5$ & $1.0 \pm 0.5$ & $0.3 \pm 0.2$ & $1.2 \pm 0.6$ & $3.3 \pm 2.0$ & $0.1 \pm 0.0^{b, c}$ \\
\hline
\end{tabular}

Calculated percentage of total cell BALF pellet and protein quantification. ${ }^{b}$ denotes significant $(p<0.05)$ versus vehicle, ${ }^{c}$ denotes significance from other AgNP particle size within a capping agent, calculated by one-way ANOVA with Tukey Post Hoc test Values expressed mean \pm SEM, $n=4-8$ 
differences in percentage of neutrophils, eosinophils, or lymphocytes.

Seven days following instillation of $20 \mathrm{~nm}$ of $110 \mathrm{~nm}$ citrate capped AgNP percentage of BAL macrophages had significantly increased compared to the citrate control, and percentage of recovered epithelial cells had decreased compared to citrate control. Seven days following instillation of citrate capped AgNP resulted in no differences in percentage of neutrophils, eosinophils, lymphocytes or BAL total protein compared to vehicle control. Instillation of $20 \mathrm{~nm}$ and $110 \mathrm{~nm}$ PVP capped AgNP resulted in no changes in percentages of macrophages, neutrophils, eosinophils, or lymphocytes compared to vehicle control 7 days following instillation. Instillation of PVP capped $110 \mathrm{~nm}$ AgNP resulted in a lower BAL protein concentration compared to PVP vehicle PVP capped AgNP.

\section{Serum cytokine concentrations following exposure to Au-AGNP}

Following intratracheal instillation of PVP or citrate capped 20 or $110 \mathrm{~nm}$ AgNP serum was collected and analyzed for concentrations of selected cytokines. The results are summarized in Figs. 1 and 2 and Additional file 1: Tables S1 and S2.

One day following IT instillation serum concentrations of IL-2 were increased by approximately 2 -fold in rats instilled with $110 \mathrm{~nm}$ citrate capped AgNP compared to vehicle control, whereas instillation of $20 \mathrm{~nm}$ AgNP elicited a moderate, and non-statistically significant increase in IL-2 (Fig. 1a). Additionally, although not statistically significant, exposure to either sized citrate capped AgNPs, appears to induce equivalent yet modest increases in serum concentrations of: IL-6 (Fig. 1c), IL-18 (Fig. 1e), and G-CSF (Fig. 1g). Seven days following AgNP all elevations in serum cytokines present at 1 day were no longer evident and levels of IL-2 (Fig. 1b), IL-6 (Fig. 1d), IL-18 (Fig. 1f), and G-CSF (Fig. 1h) were comparable or below the mean values for their vehicle control. A list of all measured serum cytokines associated with the citrated capped AgNP instillation and their mean concentrations can be found in Additional file 1: Table S1.

Exposure to PVP capped AgNP also induced limited changes in serum cytokine concentrations. Pulmonary instillation of PVP capped $20 \mathrm{~nm}$ AgNP resulted in significant elevations in IL-18 one day following exposure, while exposure to $110 \mathrm{~nm}$ PVP capped AgNP did not induce increases serum concentrations of IL-18 (Fig. 2e). In contrast to the citrate capped AgNP data, 7 days post exposure PVP capped AgNP did not have a reduction in elevated cytokines at 7 days but an increase in mean values across all cytokines. Seven days post exposure to PVP capped $20 \mathrm{~nm}$ AgNP revealed increases in IL-2
(Fig. 2b), IL-6 (Fig. 2d), and IL-18 (Fig. 2f) compared to levels 1 day post exposure. Exposure to $110 \mathrm{~nm}$ AgNP did not result in values in most serum cytokines at 1 or 7 days post instillation compared to vehicle, with the exception of IL-6 that had higher value at 7 day post instillation. A list of all measured serum cytokines and their mean concentrations associated with the PVP capped AgNP instillation can be found in Additional file 1: Table S2.

\section{Lung and heart protein oxidation}

One day following instillation of $20 \mathrm{~nm}$ citrate capped AgNP there was a modest, but non-statistically significant increase in total lung protein oxidation compared to vehicle control as determined by OxyBlot ${ }^{\mathrm{sm}}$ assay whereas, exposure to $110 \mathrm{~nm}$ citrate capped AgNP resulted in a modest decrease in lung protein oxidation (Fig. 3a and b). Instillation of PVP capped $20 \mathrm{~nm}$ AgNP also resulted in a modest increase in lung protein oxidation compared to PVP vehicle, $110 \mathrm{~nm}$ PVP capped AgNP appeared to have no impact on overall lung protein oxidation (Fig. 3c and d).

One day following instillation of $20 \mathrm{~nm}$ citrate capped AgNP also resulted in a minor increase in total heart protein oxidation, and exposure to $110 \mathrm{~nm}$ AgNP resulted in a modest reduction of heart protein oxidation compared to citrate control (Fig. 4a and b). Exposure to PVP capped $20 \mathrm{~nm}$ AgNP resulted in a decrease in total heart protein concentration compared to vehicle control and $110 \mathrm{~nm}$ PVP capped AgNP had no impact of heart protein oxidation (Fig. 4c and d).

\section{Au-AgNP Induced alterations in vascular responses}

One day or 7 days following IT exposure to AgNP or vehicle LAD coronary artery and aorta were harvested and subjected to cumulative concentration additions of the constrictors serotonin (5-HT) or phenylephrine (PE), followed by the endothelial dependent vasodilator acetylcholine (ACh) or Nitric oxide generator sodium nitroprusside (SNP).

One day following IT instillation, exposure to citrate capped $20 \mathrm{~nm}$ AgNP resulted in moderate and statistically significant, leftward shift in the concentration response curve to 5 -HT for the coronary artery compared to naive, but not the vehicle control or $110 \mathrm{~nm}$ AgNP (Fig. 5a). Exposure to PVP capped AgNP 1 day post IT instillation did not result in a shift in the concentration response compared to vehicle or naïve controls (Fig. 7b). Exposure to $110 \mathrm{~nm}$ PVP capped AgNP resulted in a statistically significant reduction in calculated $\mathrm{EC}_{50}$ value. However instillation of all other AgNP or vehicle control, 1 day post IT exposure, resulted in no changes in maximal stress generation, calculated $\mathrm{EC}_{50}$, or Hill 

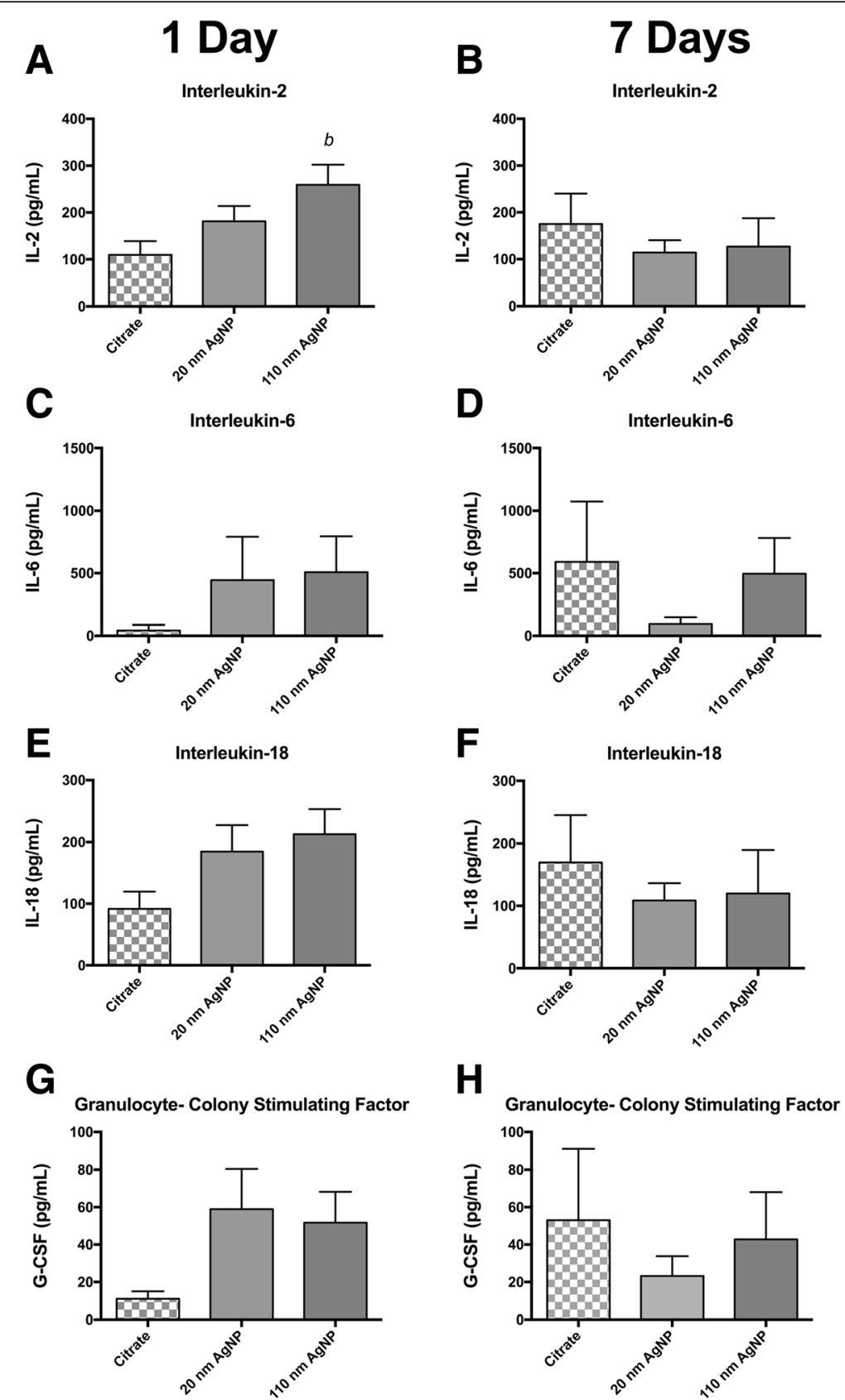

Fig. 1 Serum Cytokine Concentrations Following IT instillation of Citrate Capped AgNP. Graphs presenenting mean serum concentration of selected cytokines 1 day (panels $\mathbf{a}, \mathbf{c}, \mathbf{e}$ and $\mathbf{g}$ ) and 7 days (panels $\mathbf{b}, \mathbf{d}$, $\mathbf{f}$ and $\mathbf{h}$ ) after IT instillation. Cytokines IL-2 (a) IL-6 (c) IL-18 (d) and G-CSF (e) were modestly elevated compared to citrate vehicle 1 day following IT instillation. At 7 days following instillation cytokine concentration was not elevated above vehicle. (a) denotes statistical significance from vehicle. $p<0.05$ by one-way ANOVA, Data are reported as mean \pm SEM with $n=4$

slope values in response to $5-\mathrm{HT}$ in the coronary artery (Table 3).

One day post exposure to both citrate capped 20 and $110 \mathrm{~nm}$ AgNP resulted in a statistically significant leftward shift in concentration response curve to phenylephrine in aortic segments compared to vehicle or naïve controls (Fig. 5c). Despite the shift in concentration response curve however, there were no significant changes in aortic mean maximal stress generation, calculated $\mathrm{EC}_{50}$, or Hill slope values in response to PE (Table 4). Instillation of PVP capped AgNP did not alter concentration response curves to either 5-HT or PE in coronary artery or aorta segments, respectively, 1 day following exposure (Fig. 5b and d).

Seven days following IT instillation of $20 \mathrm{~nm}$ citrate and $110 \mathrm{~nm}$ PVP capped AgNP resulted in a leftward 

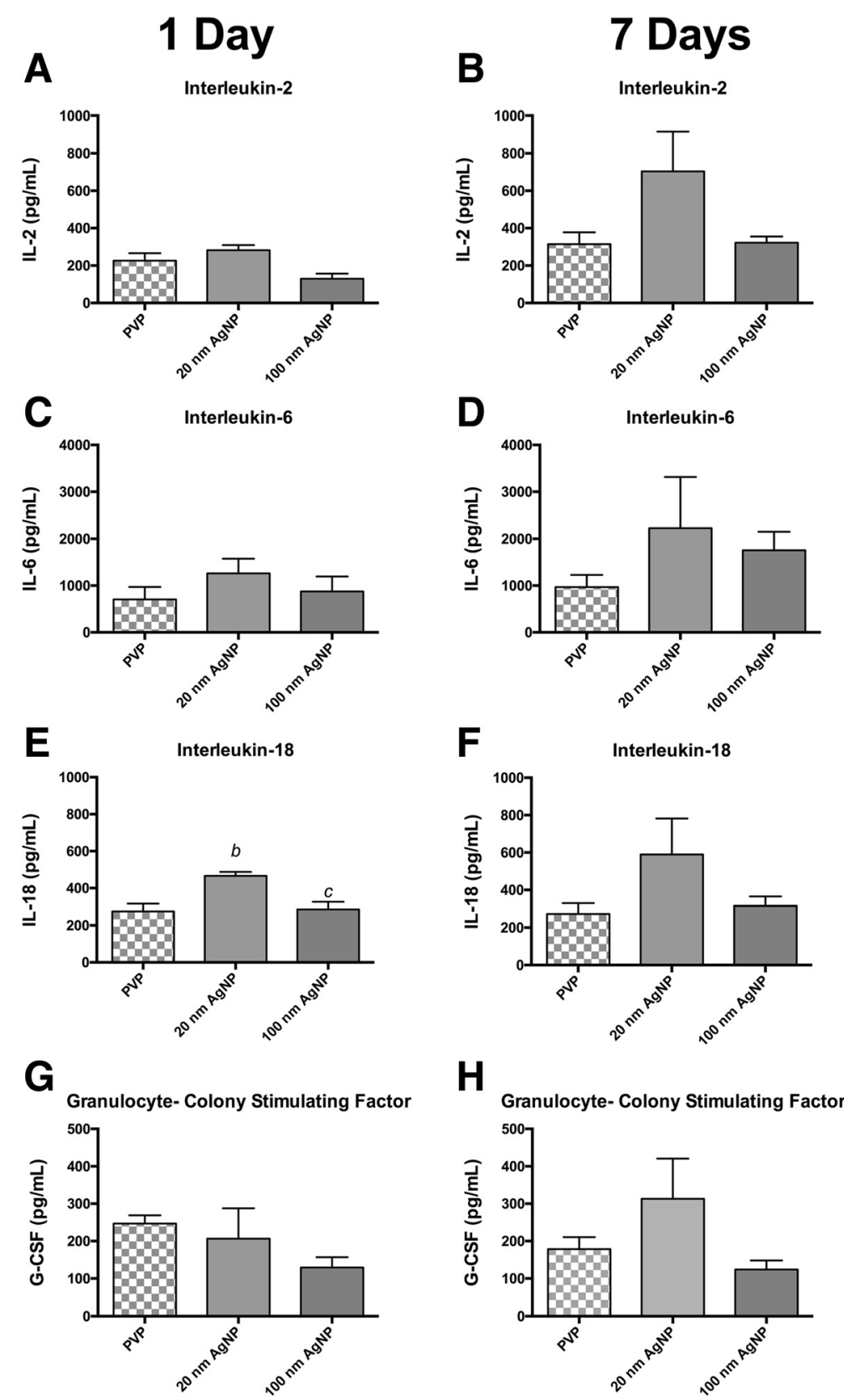

Fig. 2 Serum Cytokine Concentrations Following IT instillation of PVP Capped AgNP. Graphs presenting mean serum concentration of selected cytokines 1 day (panels $\mathbf{a}, \mathbf{c}$, e and $\mathbf{g}$ ) and 7 days (panels $\mathbf{b}, \mathbf{d}$, $\mathbf{f}$ and $\mathbf{h}$ ) after IT instillation. Cytokines IL-2 (a) IL-6 (c) IL-18 (d) and G-CSF (e) were modestly elevated compared to citrate vehicle 1 day following IT instillation. At 7 days following instillation cytokine concentration was not elevated above vehicle. (b) denotes statistical significance from vehicle, (c) denotes significance from other AgNP particle size within a capping agent. $p<0.05$ by one-way ANOVA, Data are reported as mean \pm SEM with $n=4-8$

shift in concentration response curve to 5-HT in coronary arteries (Fig. 6a and b). Interestingly, 7 days post IT instillation of citrate and PVP capped AgNP aortic segments exhibited a rightward shift in concentration response curves in response to PE (Fig. 6c and d). Exposure to AgNP or vehicle resulted in increases in mean calculated $\mathrm{EC}_{50}$ of aorta segments and decreases in maximal stress generation from both coronary (Table 3 ) and aorta segments (Table 4). No overall significant changes in Hill slope values with 5-HT or PE stimulations were observed at 1 or 7 days in either coronary or aorta segments (Tables 3 and 4).

Endothelial dependent relaxation responses were evaluated by cumulative additions of acetylcholine (ACh). One day post IT exposure to $110 \mathrm{~nm}$ citrate capped AgNP resulted in a statistically significant leftward shift 

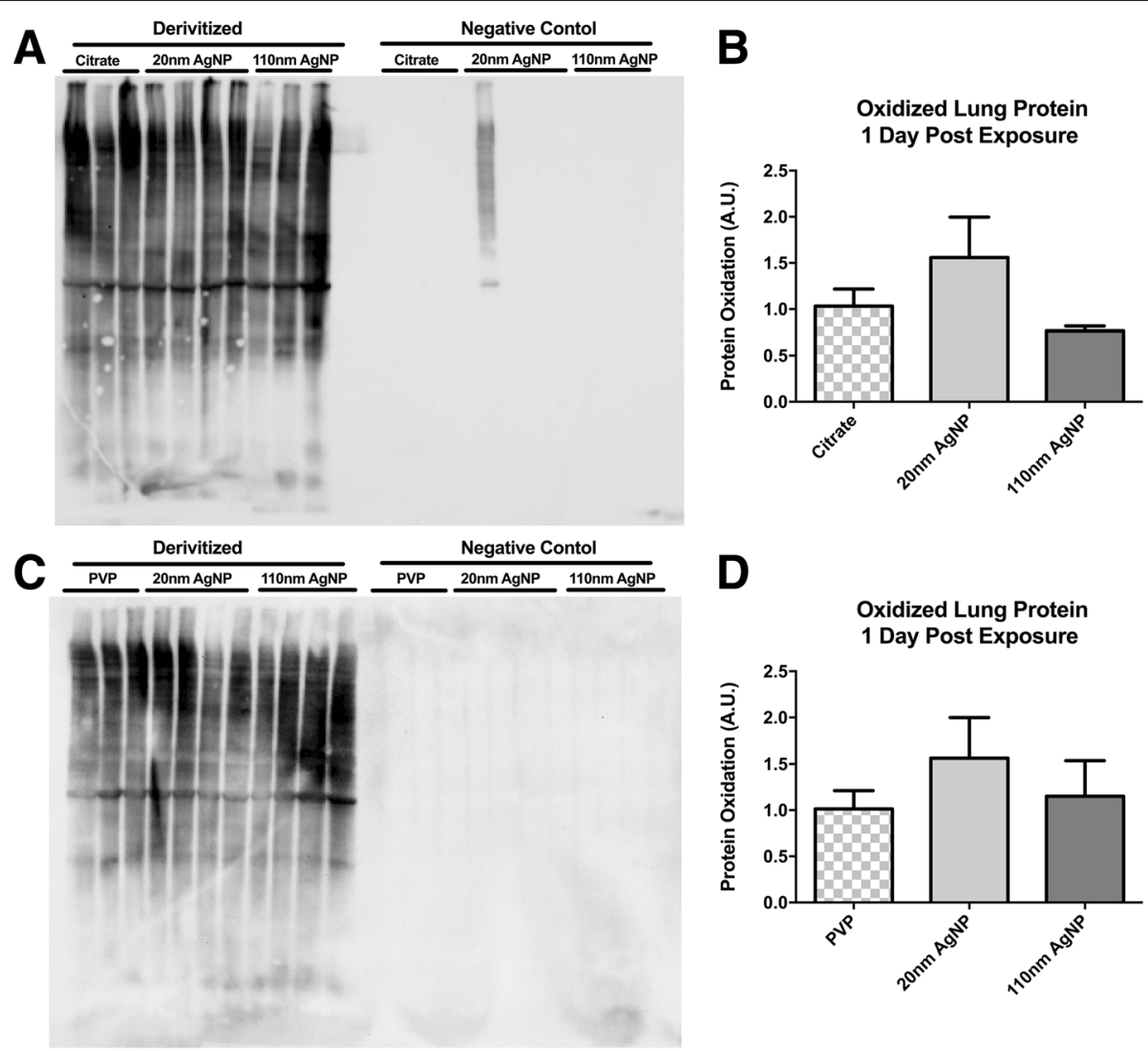

Fig. 3 Total Lung Protein Oxidation. Representative Oxyblot ${ }^{\text {TM }}$ of citrate capped AgNP exposed lung tissue (a). Semiquantitative densitomitry of citrate capped AgNP Oxyblot ${ }^{\mathrm{TM}}$ exposed lung tissue (b). Representative Oxyblot ${ }^{\mathrm{TM}}$ of PVP capped AgNP exposed lung tissue (c). Semiquantitative densitomitry of PVP capped AgNP Oxyblot ${ }^{\text {TM }}$ exposed lung tissue (d). Statistical significance $p<0.05$ by one-way ANOVA, Data are reported as mean \pm SEM with $n=3-4$

in the ACh concentration response curve of coronary arteries (Fig. 7a). Conversely, following IT exposure to citrate capped $110 \mathrm{~nm}$ AgNP there was a rightward shift in the concentration response curve to $\mathrm{ACh}$ in aortic rings (Fig. 7c). Intratracheal instillation of PVP AgNP did not result in significant changes to the response profiles (Fig. 7b and d) nor to the remaining stress following maximal concentration of $\mathrm{ACh}$, calculated $\mathrm{EC}_{50}$, or Hill slope values for coronary arteries (Tables 3 and 5) or aortic rings (Tables 4 and 5) 1 day following exposure.

Seven days post IT exposure changes in response to ACh associated with Citrate capped AgNP in coronary arteries had resolved (Fig. 8a). However, exposure to $20 \mathrm{~nm}$ and $110 \mathrm{~nm}$ PVP capped AgNP resulted in a leftward shift in the concentration response curve to $\mathrm{ACh}$ and rightward shift to the concentration response curve to PVP vehicle following exposure in coronary arteries (Fig. 8b). No differences in calculated $\mathrm{EC}_{50}$, or Hill slope values were observed at 7 days following exposure when compared to naïve coronary arteries (Table 3 ) or aortic rings (Table 4).

Aorta and coronary artery segments from animals exposed to AgNP or vehicle were treated with cumulative addition of SNP to assess an endothelial independent nitric oxide (NO) dependent relaxation. IT exposure to both citrate and PVP capped AgNP resulted in alterations in cumulative concentration responses to SNP in coronary arteries, 1 day following instillation (Fig. 9a and b). The $110 \mathrm{~nm}$ capped AgNP were capable of inducing the largest leftward shift in the concentration response curve followed by the $20 \mathrm{~nm}$ AgNP; however both were shifted leftward compared to vehicle or naïve in coronary arteries (Fig. 9a and b). Additionally, IT instillation of PVP vehicle was capable of inducing a small leftward shift in the concentration response to SNP in coronary arteries itself (Fig. 9b). The left shift in relaxation response profiles was accompanied by a reduction in calculated $\mathrm{EC}_{50}$ values for aortic rings (Table 4). However, no differences in $\mathrm{EC}_{50}$, Hill slope values or mean remaining stress following maximal concentration were observed in coronary artery segments 1 day following exposure (Table 3).

The sensitization effect to SNP on normalized relaxation response was only observed at 1 day post exposure post instillation of citrate capped AgNP in aortic rings 

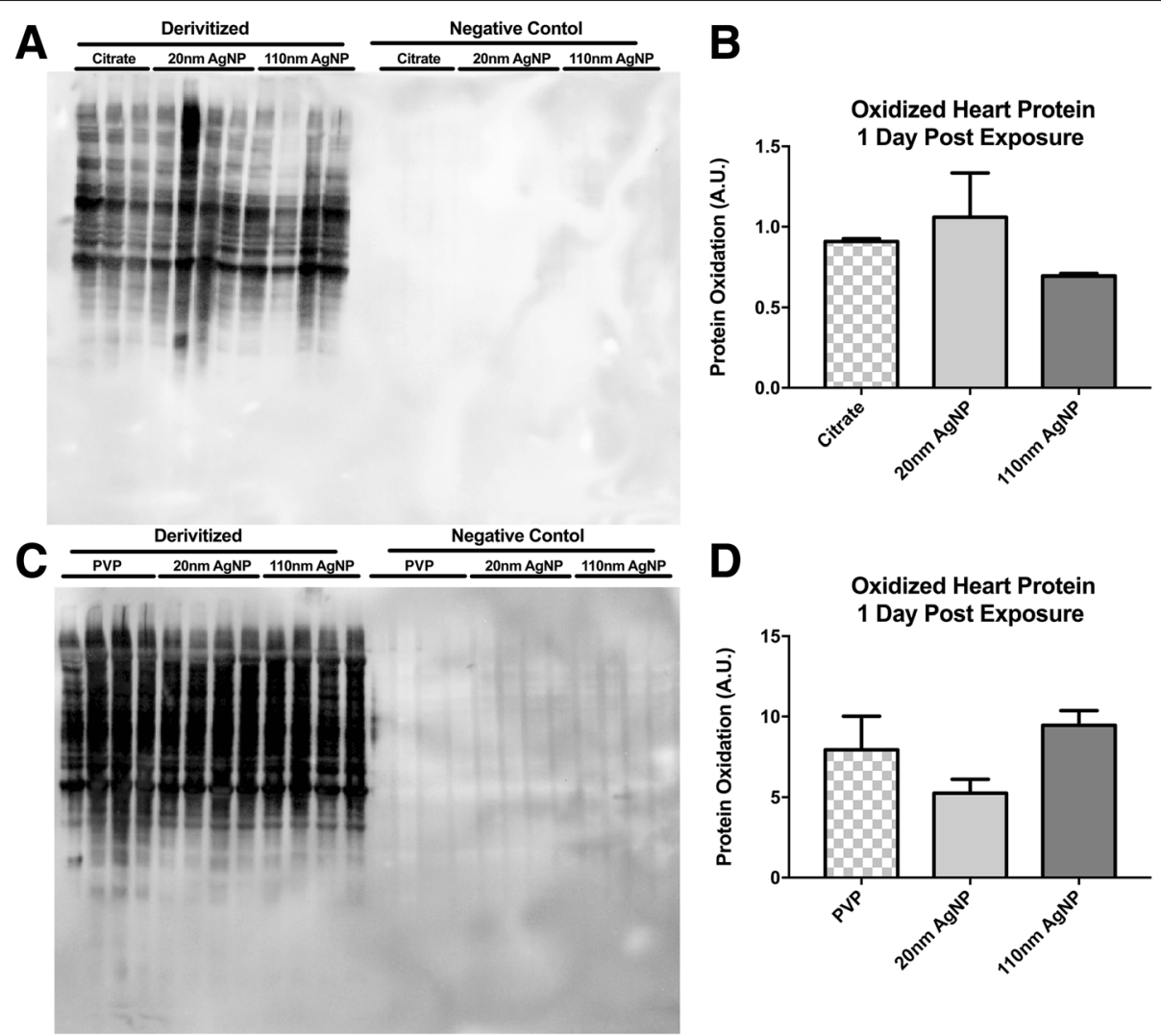

Fig. 4 Total Heart Protein Oxidation. Representative Oxyblot ${ }^{\mathrm{TM}}$ of citrate capped AgNP exposed heart tissue (a). Semiquantitative densitomitry of citrate capped AgNP Oxyblot ${ }^{T M}$ exposed heart tissue (b). Representative Oxyblot ${ }^{T M}$ of PVP capped AgNP exposed heart tissue (c). Semiquantitative densitomitry of PVP capped AgNP Oxyblot ${ }^{\text {TM }}$ exposed heart tissue (d). Statistical significance $p<0.05$ by one-way ANOVA, Data are reported as mean \pm SEM with $n=3-4$

(Fig. 9c and d). This is despite a significant decrease in calculated $\mathrm{EC}_{50}$ values of aortic rings (Table 4). However, Hill slope values, (Table 4) or remaining stress following cumulative addition of SNP (Table 5) were not different.

Seven days following exposure to AgNP only exposure to citrate $20 \mathrm{~nm}$ AgNP exhibited sensitized relaxation responses to SNP in coronary arteries. However, IT instillation of both citrate and PVP vehicle were able to induce a marked leftward shift in relaxation responses to SNP in coronary arteries (Fig. 10a and b). Coronary segments from AgNP or vehicle exposed rats demonstrated a moderate decrease in calculated $\mathrm{EC}_{50}$ value, with no differences in Hill slope value (Table 3), or remaining stress following maximal addition of SNP (Table 5).

Aortic rings demonstrated impaired endothelial independent NO dependent relaxation 7 days post IT instillation of AgNP or vehicle compared to naïve controls (Fig. 10c and d). As observed in coronary arteries exposure to the vehicle had a marked effect on SNP stress withdrawal in aortic rings at 7 days post exposure. Post exposure aortic rings exhibited increased $\mathrm{EC}_{50}$ values but no differences in Hill slope value (Table 4), and a greater remaining amount of stress following maximal SNP addition as compared to naïve (Table 5).

Au-AgNP expands cardiac $\mathrm{i} / \mathrm{r}$ injury following it instillation One or 7 days following IT exposure of AgNP or vehicle instillation rats underwent a surgically induced cardiac ischemia reperfusion $(\mathrm{I} / \mathrm{R})$ injury, in a protocol that included a $20 \mathrm{~min}$ ischemia period followed by $120 \mathrm{~min}$ of reperfusion, and were then analyzed for the extent of myocardial infarction. There was no effect of vehicle capping agents on the cardiac I/R injury 1 or 7 days post instillation (Fig. 11). One day post IT instillation both sizes of the citrate and PVP capped AgNP induced expansion of cardiac $I / R$ injury compared to naive control (Fig. 11a and b). Exposure to $20 \mathrm{~nm}$ AgNP induced expansion of cardiac I/R injury at 1 day post instillation in both capping groups compared to both vehicle and naïve. However, for the $110 \mathrm{~nm}$ particles only the PVP capped AgNP was significantly expanded compared to vehicle 1 day post instillation (Fig. 11b).

Seven days following IT instillation of AgNP or vehicle both PVP and citrate capped AgNP continued to elicit 

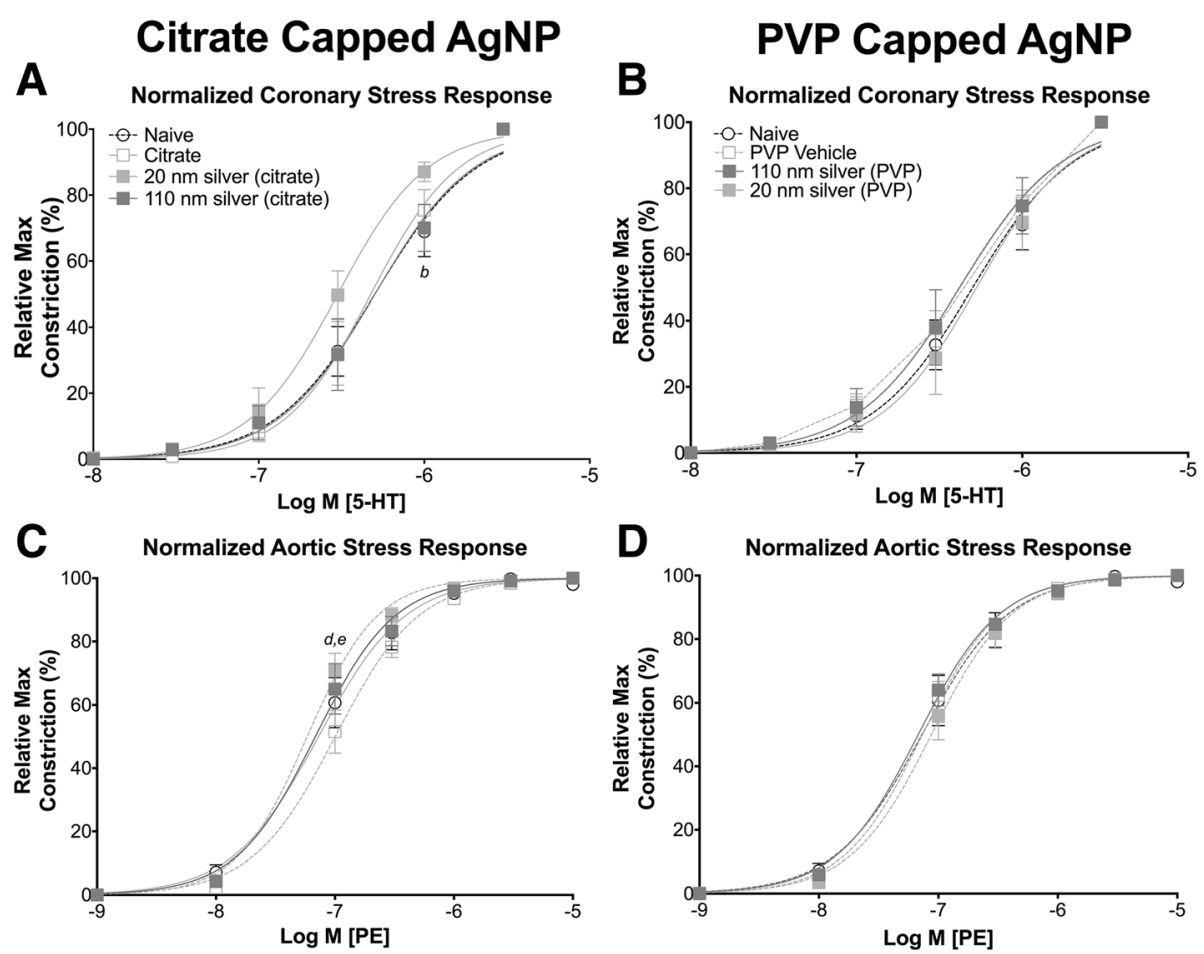

Fig. 5 Isolated Vessel Myography Constrictor Responses 1 Day post Exposure. Graphs presenting the normalized stress responses from aorta and coronary artery segments 1 day following IT exposure including: coronary responses to citrate capped AgNP (a) coronary responses to PVP capped AgNP (b) aortic responses to citrate capped AgNP (c) and aortic responses to PVP capped AgNP (d). Statistical significance $(p<0.05)$ between: naïve and $20 \mathrm{~nm}$ AgNP indicated by (b), vehicle and $20 \mathrm{~nm}$ AgNP by (d), vehicle and $110 \mathrm{~nm}$ AgNP (e), calculated by two-way ANOVA with Tukey post hoc test. Lines represent the nonliner fit to the mean data. Data are reported as mean \pm SEM with $n=3-8$

Table 3 Calculated pharmacological values for coronary artery ring constrictor and relaxation response

\begin{tabular}{|c|c|c|c|c|c|c|}
\hline \multirow{2}{*}{$\begin{array}{l}\text { Treatment } \\
\text { Group }\end{array}$} & \multicolumn{3}{|l|}{$\mathrm{EC}_{50}(\mathrm{nM})$} & \multicolumn{3}{|l|}{ Hill slope } \\
\hline & $5-\mathrm{HT}$ & ACh & SNP & $5-\mathrm{HT}$ & ACh & SNP \\
\hline Naive & $87.7 \pm 26.7$ & $103.3 \pm 28.7$ & $20.0 \pm 4.3$ & $1.3 \pm 0.1$ & $1.8 \pm 0.2$ & $1.1 \pm 0.1$ \\
\hline \multicolumn{7}{|c|}{1 Day Post IT Exposure } \\
\hline Citrate & $105.9 \pm 17.1$ & $75.6 \pm 7.4$ & $31.0 \pm 5.3$ & $1.3 \pm 0.1$ & $1.7 \pm 0.1$ & $1.2 \pm 0.1$ \\
\hline $20 \mathrm{~nm}$ AgNP & $60.2 \pm 8.4$ & $132.8 \pm 56.8$ & $22.0 \pm 3.4$ & $1.5 \pm 0.1$ & $1.5 \pm 0.1$ & $1.1 \pm 0.1$ \\
\hline 110 nm AgNP & $75.5 \pm 16.3$ & $147.6 \pm 51.0$ & $28.1 \pm 4.8$ & $1.4 \pm 0.1$ & $1.6 \pm 0.1$ & $1.1 \pm 0.1$ \\
\hline PVP & $79.5 \pm 11.5$ & $115.7 \pm 30.5$ & $20.9 \pm 3.4$ & $1.4 \pm 0.1$ & $1.7 \pm 0.2$ & $1.2 \pm 0.1$ \\
\hline $20 \mathrm{~nm}$ AgNP & $95.1 \pm 20.1$ & $95.3 \pm 3.0$ & $18.9 \pm 3.2$ & $1.4 \pm 0.1$ & $1.5 \pm 0.0$ & $1.2 \pm 0.1$ \\
\hline 110 nm AgNP & $70.0 \pm 10.2^{a}$ & $147.6 \pm 51.0$ & $23.0 \pm 2.4$ & $1.3 \pm 0.1$ & $1.8 \pm 0.2$ & $1.1 \pm 0.1$ \\
\hline \multicolumn{7}{|c|}{7 Day Post IT Exposure } \\
\hline Citrate & $799.6 \pm 395.9$ & $57.4 \pm 1.2$ & $67.1 \pm 33.9$ & $1.2 \pm 0.4$ & $1.5 \pm 0.0$ & $1.0 \pm 0.1$ \\
\hline $20 \mathrm{~nm}$ AgNP & $264.2 \pm 74.9$ & $112.9 \pm 29.0$ & $55.7 \pm 8.2$ & $1.1 \pm 0.2$ & $1.6 \pm 0.2$ & $1.1 \pm 0.1$ \\
\hline 110 nm AgNP & $954.6 \pm 80.8$ & $98.3 \pm 11.6$ & $59.3 \pm 12.5$ & $1.1 \pm 0.2$ & $1.9 \pm 0.1$ & $1.3 \pm 0.3$ \\
\hline PVP & $237.7 \pm 61.1$ & $89.2 \pm 25.9$ & $48.8 \pm 3.6$ & $1.1 \pm 0.2$ & $1.6 \pm 0.3$ & $1.2 \pm 0.1$ \\
\hline $20 \mathrm{~nm}$ AgNP & $140.8 \pm 31.3$ & $117.5 \pm 26.3$ & $41.0 \pm 3.6$ & $1.2 \pm 0.2$ & $1.5 \pm 0.1$ & $1.0 \pm 0.1$ \\
\hline $110 \mathrm{~nm}$ AgNP & $306.0 \pm 70.3^{a}$ & $110.2 \pm 39.4$ & $50.7 \pm 13.3$ & $1.1 \pm 0.2$ & $1.6 \pm 0.2$ & $1.2 \pm 0.1$ \\
\hline
\end{tabular}

The calculated mean $\mathrm{EC}_{50}$ and Hill slope, responses of LAD coronary artery segment to serotonin (5-HT), acetylcholine (ACh), and sodium nitroprusside (SNP) 1 day and 7 days following $200 \mu \mathrm{l}$ instillation of Citrate or PVP vehicle or $200 \mu \mathrm{g} 20$ or $110 \mathrm{~nm}$ AgNP. Values expressed mean \pm SEM. ${ }^{a}$ denotes significant versus Naïve $(p<0.05)$ calculated by one-way ANOVA with Tukey Post Hoc test, $n=3-8$ 
Table 4 Calculated pharmacological values for aortic ring constrictor and relaxation response

\begin{tabular}{|c|c|c|c|c|c|c|}
\hline \multirow{2}{*}{$\begin{array}{l}\text { Treatment } \\
\text { Group }\end{array}$} & \multicolumn{3}{|l|}{$\mathrm{EC}_{50}(\mathrm{nM})$} & \multicolumn{3}{|l|}{ Hill slope } \\
\hline & PE & $\mathrm{ACh}$ & SNP & PE & $\mathrm{ACh}$ & SNP \\
\hline Naive & $565.9 \pm 129.8$ & $127.4 \pm 19.4$ & $104.1 \pm 25.3$ & $1.7 \pm 0.2$ & $1.8 \pm 0.3$ & $2.1 \pm 0.4$ \\
\hline \multicolumn{7}{|c|}{1 Day Post IT Exposure } \\
\hline Citrate & $501.9 \pm 125.4$ & $108.8 \pm 47.0$ & $74.3 \pm 29.5$ & $1.8 \pm 0.2$ & $1.4 \pm 0.3$ & $1.8 \pm 0.2$ \\
\hline $20 \mathrm{~nm}$ AgNP & $311.4 \pm 58.1$ & $97.79 \pm 17.9$ & $28.6 \pm 8.0$ & $1.7 \pm 0.1$ & $1.5 \pm 0.1$ & $1.8 \pm 0.2$ \\
\hline 110 nm AgNP & $558.5 \pm 122.2$ & $58.45 \pm 18.1$ & $20.9 \pm 4.2$ & $1.7 \pm 0.2$ & $1.8 \pm 0.5$ & $1.8 \pm 0.3$ \\
\hline PVP & $450.2 \pm 60.3$ & $101.9 \pm 20.7$ & $44.8 \pm 4.8^{a}$ & $1.5 \pm 0.0$ & $1.7 \pm 0.1$ & $1.7 \pm 0.1$ \\
\hline $20 \mathrm{~nm}$ AgNP & $593.0 \pm 161.8$ & $121.6 \pm 31.9$ & $40.5 \pm 10.6^{a}$ & $1.9 \pm 0.4$ & $1.6 \pm 0.1$ & $1.8 \pm 0.2$ \\
\hline $110 \mathrm{~nm}$ AgNP & $490.8 \pm 156.2$ & $119.3 \pm 20.1$ & $20.9 \pm 4.2^{a}$ & $1.7 \pm 0.2$ & $1.7 \pm 0.4$ & $1.9 \pm 0.4$ \\
\hline \multicolumn{7}{|c|}{7 Day Post IT Exposure } \\
\hline Citrate & $497.6 \pm 11.8$ & $106.1 \pm 57.9$ & $26.4 \pm 6.6^{a}$ & $1.8 \pm 0.2$ & $1.8 \pm 0.2$ & $1.7 \pm 0.2$ \\
\hline $20 \mathrm{~nm}$ AgNP & $256.2 \pm 58.0$ & $63.4 \pm 7.4$ & $45.1 \pm 1.0^{a}$ & $1.6 \pm 0.1$ & $1.6 \pm 0.1$ & $1.6 \pm 0.2$ \\
\hline 110 nm AgNP & $540.4 \pm 18.0$ & $84.2 \pm 26.3$ & $66.3 \pm 29.3$ & $1.6 \pm 0.1$ & $1.6 \pm 0.1$ & $1.8 \pm 0.1$ \\
\hline PVP & $215.0 \pm 15.0$ & $196.6 \pm 82.2$ & $40.1 \pm 18.8$ & $1.1 \pm 0.1$ & $1.5 \pm 0.4$ & $1.7 \pm 0.4$ \\
\hline $20 \mathrm{~nm}$ AgNP & $122.9 \pm 14.1^{a}$ & $120.0 \pm 13.2$ & $66.6 \pm 14.9$ & $1.1 \pm 0.1$ & $1.1 \pm 0.2$ & $1.5 \pm 0.2$ \\
\hline $110 \mathrm{~nm}$ AgNP & $260.3 \pm 50.0$ & $66.2 \pm 17.7$ & $66.4 \pm 10.6$ & $1.1 \pm 0.0$ & $2.0 \pm 0.3$ & $1.5 \pm 0.4$ \\
\hline
\end{tabular}

The calculated mean $\mathrm{EC}_{50}$, and Hill slope, responses of aorta segment to phenylephrine (PE), acetylcholine (ACh), and sodium nitroprusside (SNP) 1 day and 7 days post $200 \mu \mathrm{l}$ instillation of Citrate or PVP vehicle or $200 \mu \mathrm{g} 20$ or $110 \mathrm{~nm}$ AgNP. Values expressed mean \pm SEM. ${ }^{a}$ denotes significant versus Naïve ( $p<0.05$ ) calculated by one-way ANOVA with Tukey Post Hoc test, $n=3-8$

expansion of the cardiac $\mathrm{I} / \mathrm{R}$ injury. Both citrate and PVP capped $20 \mathrm{~nm}$ AgNP induced greater expansion of cardiac I/R injury compared to vehicle or naïve (Fig. 11c and d). PVP capped $110 \mathrm{~nm}$ AgNP was also capable of expanding cardiac I/R injury compared to vehicle and naïve, but citrate capped $110 \mathrm{~nm}$ AgNP only expanded cardiac I/R injury compared to vehicle. Additionally, at 7 days post IT exposure to citrate capped $20 \mathrm{~nm}$ AgNP induced greater expansion of cardiac I/R injury that citrate capped $110 \mathrm{~nm}$ AgNP.

\section{Discussion}

The rapidly expanding uses of ENMs have raised questions regarding their safety following exposure to such materials. To date, there is little consensus regarding the safety of engineered nanomaterials, the mechanisms by which they may induce a toxic response, or how these mechanisms may be influenced by particle size or modifications such as addition of capping agents. There is current literature evidence that pulmonary exposure to $\mathrm{PM}$ and ENMs can alter to progression of or to cardiovascular disease (CVD) and dysfunction through multiple pathways, including inflammation [15, 33, 36], autonomic dysfunction $[25,37,38]$, oxidative stress [39-41] or mitochondrial dysfunction [42, 43]. We evaluated the impact of a pulmonary exposure to 2 different sized silver nanoparticles (AgNP) with different capping agents on pulmonary BAL cells and protein, serum cytokine (as a surrogate for systemic inflammation), protein oxidation in lung and heart, vascular function, and myocardial ischemia reperfusion (I/R) injury. Using a dose of $200 \mu \mathrm{g}$ of AgNP which was selected by the NCNHIR consortium as a high exposure range and proof of concept dose in line with similar dosing used by other consortium investigators [29] capable of potential toxicological effects but not mortality or morbidity of the animals. This dose may not reflect a viable paradigm of human exposure, however this dosage is estimated to be approximately 720 times that of the limit for human exposure [31]. We hypothesized that intratracheal (IT) instillation of AgNP would result expansion of $I / R$ injury, possibly mediated through a circulating inflammation signal and resulting in vascular dysfunction which is sensitive to particle size as well as capping agent. This hypothesis was based on the interpretation of effects of previously investigated ENMs including but not limited to: fullerenes [23], Multiwall Carbon Nanotubes (MWCNTs) [24] and most recently another species of AgNP [27].

In order to assess the inflammatory response, we evaluated BAL immune cells and total protein levels, serum levels of several cytokines and chemokines that are known to be associated with either particulate matter (PM) exposure or cardiovascular disease, as well as examining protein oxidation of lung and heart tissue. Exposure to AgNP had very little impact on increasing numbers of neutrophils, lymphocytes or eosinophils, only decreases in total percentages of macrophages were impacted at 1 day, leading to a rise in total percentage of recovered epithelial cells. However, in the absence of 


\section{Citrate Capped AgNP}

A

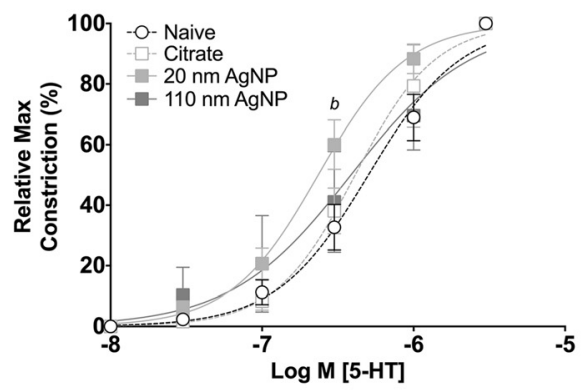

C Normalized Aortic Stress Response

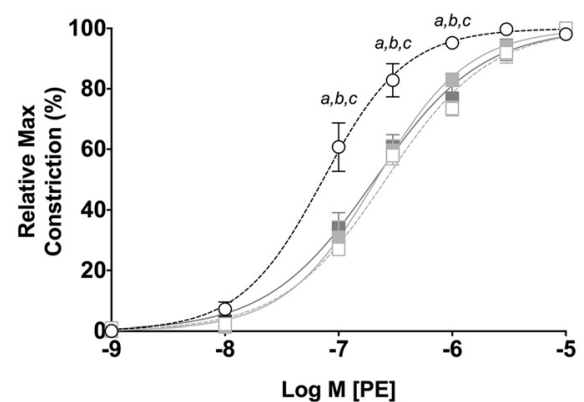

PVP Capped AgNP
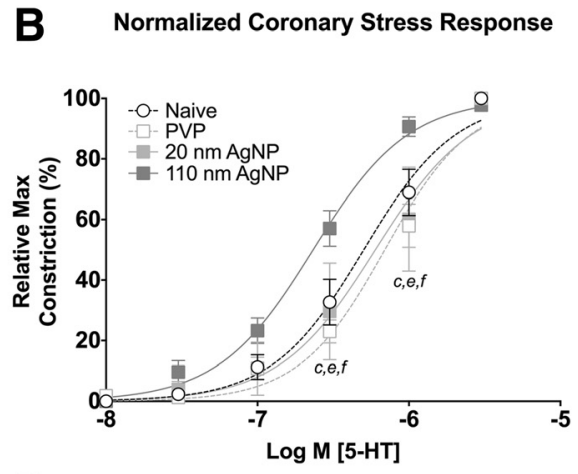

D Normalized Aortic Stress Response

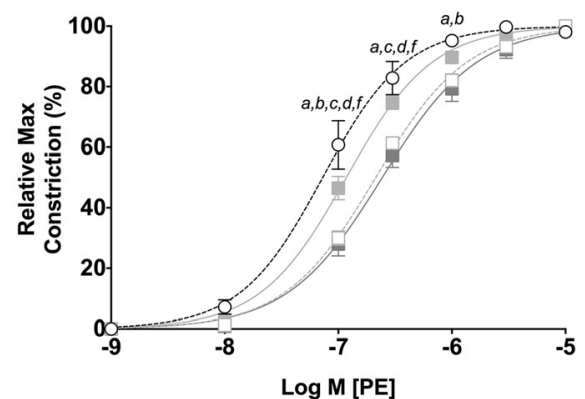

Fig. 6 Isolated Vessel Myography Constrictor Responses 7 Days post Exposure. Graphs presenting the normalized stress responses of aorta and coronary artery segments 7 days following IT exposure including: coronary responses to citrate capped AgNP (a) coronary responses to PVP capped AgNP (b) aortic responses to citrate capped AgNP (c) and aortic responses to PVP capped AgNP (d). Statistical significance $(p<0.05)$ between: naïve and vehicle indicated by (a), naïve and $20 \mathrm{~nm}$ AgNP indicated by (b), naïve and $110 \mathrm{~nm}$ AgNP indicated by (c), vehicle and $20 \mathrm{~nm}$ AgNP, vehicle and $110 \mathrm{~nm} \operatorname{AgNP}(e), 20 \mathrm{~nm}$ AgNP and $110 \mathrm{~nm}$ AgNP by (f), calculated by two-way ANOVA with Tukey post hoc test Lines represent the nonliner fit to the mean data. Data are reported as mean \pm SEM with $n=3-4$

major changes in BAL total protein it is likely these epithelial cells reflect BAL technique rather than AgNP associated epithelial damage or increase in lung permeability. It is interesting to note that despite utilization of the same particles and a roughly equivalent dose our investigation demonstrated lower percentages of inflammatory cells at 1 and 7 days than other investigations $[11,12]$.

Collected serum samples revealed no observed temporal relationship between IT instillation of AgNP and circulating levels of cytokines. Although, cardiovascular disease and dysfunction are associated with increases in inflammatory cytokines such as IL-6 [44, 45] and IL$18[46,47]$ the large extent of cardiac I/R injury reported here does not correlate with the small changes in circulating cytokines. Although not directly related to cardiac I/R injury, IL-2 may mediate organ specific pro-inflammatory response through control of T-cell differentiation and control of Th2 cytokine production $[48,49]$. The lack of correlation between circulating cytokines and the extent of $I / R$ injury we report here suggests that the observed cytokine response is not likely the primary underlying mechanism for driving the expansion of cardiac injury. Increases in serum IL-2, IL-6, and IL-18 that were only observed in rats exposed to $20 \mathrm{~nm}$ AgNP, may indicate the influence of particle size and capping agent. Overall, we found that exposure to PVP or citrate capped $20 \mathrm{~nm}$ or $110 \mathrm{~nm}$ AgNP had minimal impact on lung and heart protein oxidation suggesting that the source of inflammation by not be related to metal induced oxidative stress, as previously observed in other studies [40, 43, 50, 51]. It is interesting that there lack of reports examining general protein oxidation in response to silver exposures in cardiac tissues. We also recognize the potential importance of lipid oxidation that may occur and the close to ties to the oxidant/ antioxidant balance that was not examined in this study but likely underlie the reports of oxidative stress following exposure. Our findings may support an alternative hypothesis for the general effect of a pulmonary exposure to EM, one in which the EM may not directly induce an significant initial inflammatory response but exacerbate an inflammatory response to a secondary insult, such as been described following 
Citrate Capped AgNP
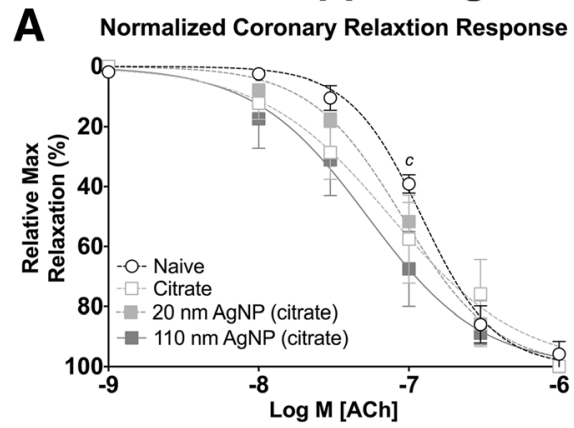

C Normalized Aortic Relaxtion Response

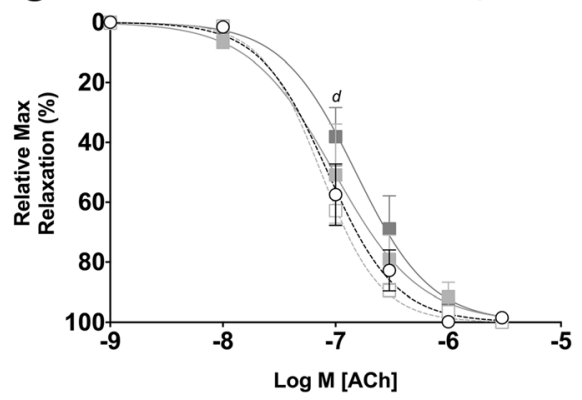

PVP Capped AgNP

B Normalized Coronary Relaxtion Response

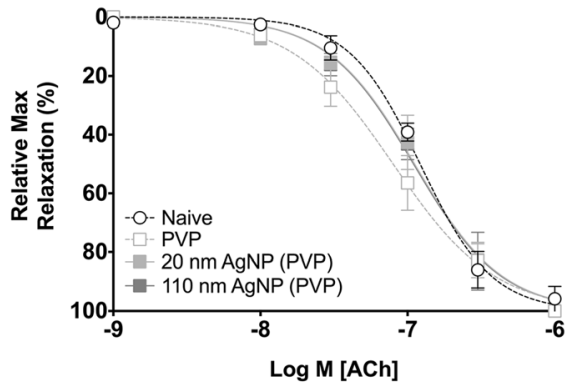

D Normalized Aortic Relaxtion Response

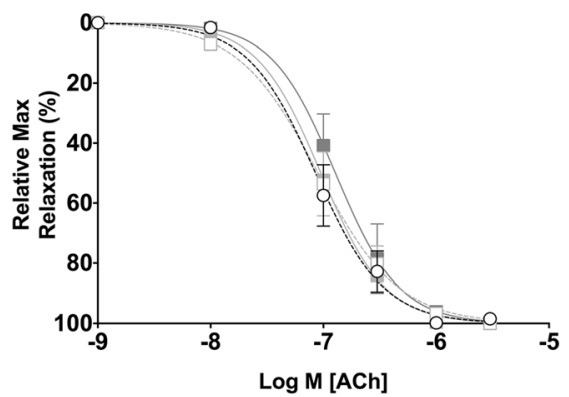

Fig. 7 Isolated Vessel Myography ACh Responses 1 Day post Exposure. Graphs presenting the normalized stress responses of aorta and coronary artery segments 1 day following IT exposure including: coronary responses to citrate capped AgNP (a) coronary responses to PVP capped AgNP (b) aortic responses to citrate capped AgNP (c) and aortic responses to PVP capped AgNP (d). Statistical significance between naïve and $110 \mathrm{~nm}$ AgNP $(p<0.05)$ indicated by $(c)$, vehicle and $20 \mathrm{~nm}$ AgNP indicated by $(d)$, calculated by two-way ANOVA with Tukey post hoc test. Lines represent the nonliner fit to the mean data. Data are reported as mean \pm SEM with $n=3-8$

Table 5 Calculated vascular stress values for coronary arteries and aortic rings

\begin{tabular}{|c|c|c|c|c|c|c|}
\hline \multirow{3}{*}{$\begin{array}{l}\text { Treatment } \\
\text { Group }\end{array}$} & \multicolumn{3}{|l|}{ Coronary Artery } & \multicolumn{3}{|l|}{ Aorta } \\
\hline & \multirow{2}{*}{$\begin{array}{l}\text { Maximal Stress Generation } \\
\left(\mathrm{mN} / \mathrm{mm}^{2}\right) \\
5-\mathrm{HT}\end{array}$} & \multicolumn{2}{|c|}{$\begin{array}{l}\text { Remaining Stress } \\
\left(\mathrm{mN} / \mathrm{mm}^{2}\right)\end{array}$} & \multirow{2}{*}{$\begin{array}{l}\text { Maximal Stress Generation } \\
\left(\mathrm{mN} / \mathrm{mm}^{2}\right) \\
5-\mathrm{HT}\end{array}$} & \multicolumn{2}{|c|}{$\begin{array}{l}\text { Remaining Stress } \\
\left(\mathrm{mN} / \mathrm{mm}^{2}\right)\end{array}$} \\
\hline & & $\overline{\mathrm{ACh}}$ & SNP & & $\overline{A C h}$ & SNP \\
\hline Naive & $4.0 \pm 0.5$ & $0.1 \pm 0.1$ & $0.0 \pm 0.1$ & $4.0 \pm 0.5$ & $0.1 \pm 0.1$ & $0.0 \pm 0.1$ \\
\hline \multicolumn{7}{|c|}{1 Day Post IT Exposure } \\
\hline Citrate & $3.5 \pm 0.4$ & $1.2 \pm 0.9$ & $0.0 \pm 0.1$ & $3.5 \pm 0.4$ & $1.2 \pm 0.9$ & $0.0 \pm 0.1$ \\
\hline $20 \mathrm{~nm}$ AgNP & $4.3 \pm 0.5$ & $0.3 \pm 0.2$ & $0.0 \pm 0.1$ & $4.3 \pm 0.5$ & $0.3 \pm 0.2$ & $0.0 \pm 0.1$ \\
\hline 110 nm AgNP & $3.2 \pm 0.4$ & $0.8 \pm 0.5$ & $0.0 \pm 0.1$ & $3.2 \pm 0.4$ & $0.8 \pm 0.5$ & $0.0 \pm 0.1$ \\
\hline PVP & $3.4 \pm 0.3$ & $0.4 \pm 0.3$ & $0.1 \pm 0.1$ & $3.4 \pm 0.3$ & $0.4 \pm 0.3$ & $0.1 \pm 0.1$ \\
\hline $20 \mathrm{~nm}$ AgNP & $2.7 \pm 0.4$ & $0.3 \pm 0.2$ & $0.0 \pm 0.1$ & $2.7 \pm 0.4$ & $0.3 \pm 0.2$ & $0.0 \pm 0.1$ \\
\hline 110 nm AgNP & $3.0 \pm 0.5$ & $0.4 \pm 0.1$ & $0.0 \pm 0.1$ & $3.0 \pm 0.5$ & $0.4 \pm 0.1$ & $0.0 \pm 0.1$ \\
\hline \multicolumn{7}{|c|}{7 Day Post IT Exposure } \\
\hline Citrate & $2.4 \pm 0.9$ & $0.4 \pm 0.4$ & $-0.1 \pm 0.1$ & $2.4 \pm 0.9$ & $0.0 \pm 0.1$ & $0.6 \pm 0.2$ \\
\hline $20 \mathrm{~nm}$ AgNP & $3.6 \pm 0.4$ & $-0.1 \pm 0.4$ & $0.1 \pm 0.5$ & $3.6 \pm 0.4$ & $0.3 \pm 0.1$ & $0.4 \pm 0.2$ \\
\hline 110 nm AgNP & $2.8 \pm 0.8$ & $0.1 \pm 0.1$ & $-0.2 \pm 0.1$ & $2.8 \pm 0.8$ & $0.3 \pm 0.3$ & $0.0 \pm 0.1$ \\
\hline PVP & $1.7 \pm 0.7$ & $0.1 \pm 0.0$ & $-0.3 \pm 0.1$ & $1.7 \pm 0.7$ & $0.5 \pm 0.4$ & $0.5 \pm 0.2$ \\
\hline $20 \mathrm{~nm}$ AgNP & $1.6 \pm 0.5$ & $0.6 \pm 0.5$ & $-0.4 \pm 0.1$ & $1.6 \pm 0.5$ & $0.6 \pm 0.6$ & $0.4 \pm 0.1$ \\
\hline 110 nm AgNP & $3.0 \pm 0.6$ & $0.1 \pm 0.2$ & $-0.1 \pm 0.2$ & $3.0 \pm 0.6$ & $0.5 \pm 0.3$ & $0.2 \pm 0.3$ \\
\hline
\end{tabular}

The calculated mean maximum stress generated to serotonin (5-HT) or phenylephrine (PE) in coronary arteries and aortic rings respectively. Calculated remaining stress values following acetylcholine (ACh) or sodium nitroprusside (SNP) withdrawal. Values expressed mean \pm SEM $n=3-8$ 


\section{Citrate Capped AgNP}

A Normalized Coronary Relaxation Response

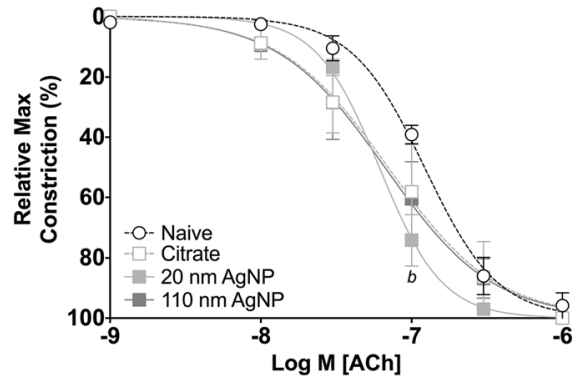

C Normalized Aortic Relaxation Response

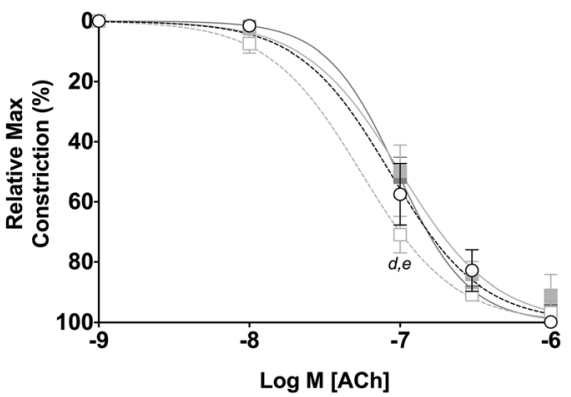

PVP Capped AgNP

B Normalized Coronary Relaxation Response

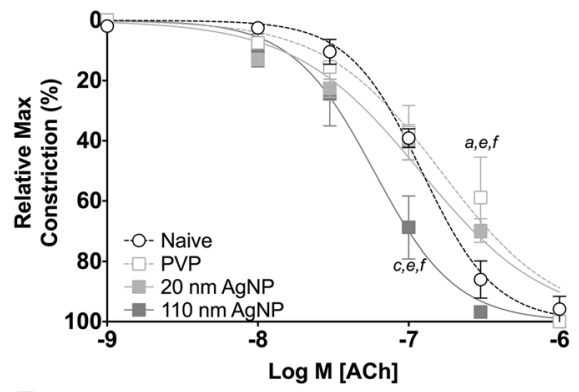

D Normalized Aortic Relaxation Response

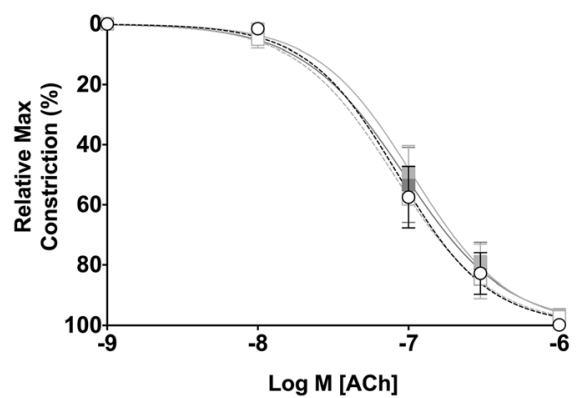

Fig. 8 Isolated Vessel Myography ACh Responses 7 Days post Exposure. Graphs presenting the normalized stress responses of aorta and coronary artery segments 7 days following IT exposure including: coronary responses to citrate capped AgNP (a) coronary responses to PVP capped AgNP (b) aortic responses to citrate capped AgNP (c) and aortic responses to PVP capped AgNP (d). Statistical significance $(p<0.05)$ between: naïve and vehicle indicated by (a), naïve and $20 \mathrm{~nm}$ AgNP indicated by (b), naïve and $110 \mathrm{~nm}$ AgNP indicated by (c), vehicle and $20 \mathrm{~nm}$ AgNP, vehicle and $110 \mathrm{~nm} \operatorname{AgNP}(e), 20 \mathrm{~nm}$ AgNP and $110 \mathrm{~nm}$ AgNP by (f), calculated by two-way ANOVA with Tukey post hoc test. Lines represent the nonliner fit to the mean values. Data are reported as mean \pm SEM with $n=3-4$

inoculation with lipopolysaccharide (LPS) [52] or immune sensitization in asthma models associated with both vascular dysfunction and expansion of myocardial infarction [53]. Previous studies investigating the EMN exposure and pulmonary fibrosis in rats demonstrated that exposure to nanomaterials alone were insufficient to induce fibrosis. However, inoculation with LPS following MWCNT exposure was able to induce greater fibrotic changes than LPS or MWCNT alone (25). Our data may provide evidence for the ability for AgNP to exacerbate inflammatory responses within $I / R$ injury and ultimately expand myocardial I/R injury. Although we were unable to demonstrate a strong inflammatory response (through serum cytokine levels) following instillation of AgNP, analysis of cytokines localized to tissues of interest, such as myocardium or the vasculature could be a more enlightening target of investigation.

Overall, the limited changes in circulating cytokine concentrations post exposure to AgNP may result in priming of elements of the immune system for a secondary insult response and correlate with capping agents and particle size. Instillation of $20 \mathrm{~nm}$ PVP capped AgNP induced a greater rise in concentrations of select cytokines (i.e., IL-2, IL-6, IL-18) compared to citrate capped AgNP or their vehicle controls; while PVP and citrate capped AgNP $110 \mathrm{~nm}$ particles resulted in no significant differences from vehicle controls and in general the cardiac I/R injury was slightly greater and prolonged. These results allow us to suggest that a combination capping agent and particle size may be an important factor when evaluating the toxicity associated with exposure to AgNP [54].

The differential response to various particle sizes and capping agents on particles may be related to the content of protein coronas formed on the particles and reflect differing biological interactions [55]. The formation of unique protein coronas based on the capping material has been reported to influence the inflammatory response to AgNP by modulating the way nanomaterials interact with cells or tissues [56-58]. One study of gold nanoparticles revealed different capping agents have the ability to elicit differential effects on both in vitro and in vivo toxicity [59]. The results of this study allow us to suggest that different capping agents may have the ability to change the manner in which capped AgNP may impact toxicity [58,60,61] or contribute to the observed vehicle effects in our model of a cardiovascular injury response. 


\section{Citrate Capped AgNP}

A
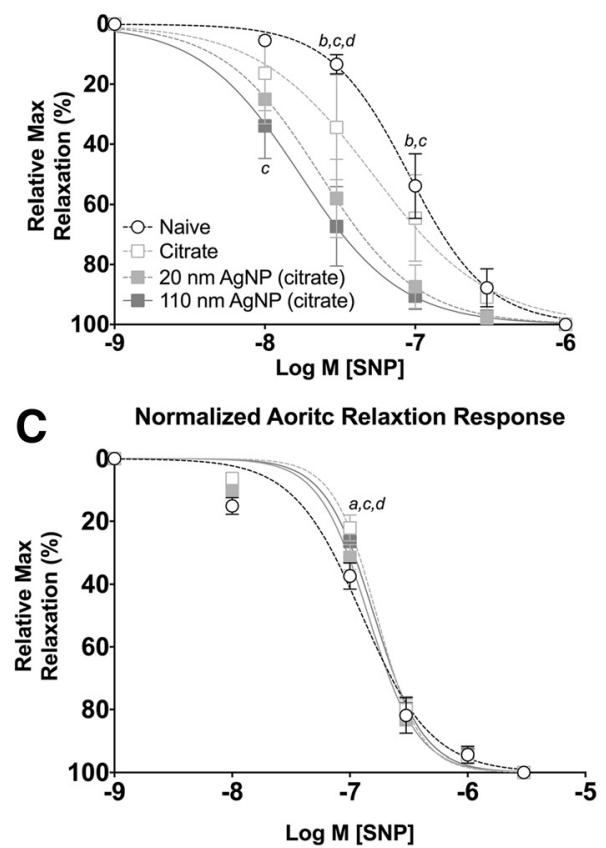

PVP Capped AgNP

B Normalized Coronary Relaxtion Response

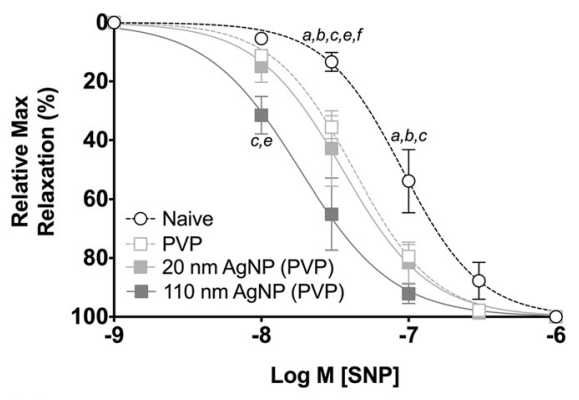

D Normalized Aortic Relaxtion Response

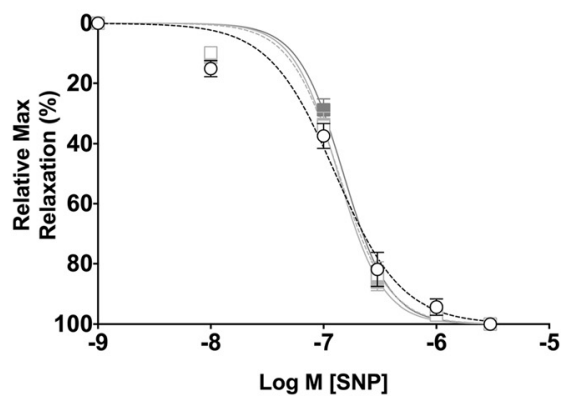

Fig. 9 Isolated Vessel Myography SNP Responses 1 Day post Exposure. Graphs presenting the normalized stress responses of aorta and coronary artery segments 1 day following IT exposure including: coronary responses to citrate capped AgNP (a) coronary responses to PVP capped AgNP (b) aortic responses to citrate capped AgNP (c) and aortic responses to PVP capped AgNP (d). Statistical significance $(p<0.05)$ between: naïve and vehicle indicated by (a), naïve and $20 \mathrm{~nm}$ AgNP indicated by (b), naïve and $110 \mathrm{~nm}$ AgNP indicated by (c), vehicle and $20 \mathrm{~nm}$ AgNP, vehicle and $20 \mathrm{~nm}$ AgNP by (d), vehicle and $110 \mathrm{~nm}$ AgNP (e), $20 \mathrm{~nm}$ AgNP and $110 \mathrm{~nm}$ AgNP by (f), calculated by two-way ANOVA with Tukey post hoc test. Lines represent the nonliner fit to the mean values. Data are reported as mean \pm SEM with $n=3-8$

An additional aspect of the toxicological impact of AgNP on the cardiovascular system evaluated by this study was the duration of effect. In this study we observed changes in serum cytokines, vascular reactivity, and $I / R$ injury that varied between particle size and capping agents as well as days post instillation. These observations may suggest a time-dependent aspect of particle size-capping interactions.

It should be noted that the impact of AgNP seems highly dependent upon the vascular bed examined, as well as being influenced by the duration of time following exposure, whereby the smaller diameter coronary vessels seem more susceptible to changes associated with exposure to AgNP at earlier time points than the aorta. This observation in itself is not unexpected and has been reported in a variety of studies following exposure to other materials $[26,62,63]$. Despite the smaller $20 \mathrm{~nm}$ particle seeming to have a stronger impact on inducing an inflammatory response or overall expansion of cardiac I/R injury, the larger $110 \mathrm{~nm}$ particle seems to impart the greatest influence of vascular reactivity. Whether or not moderate changes in vascular reactivity are driven by inflammation or may in fact drive expansion of cardiac I/R injury remain unresolved. It should also be noted that we observed vascular changes associated with IT instillation of both PVP and Citrate vehicles. This vehicle effect suggests that the capping agent may strongly influence observed endpoints. However, this study adds to a body of evidence that exposure to nanoscale particles can influence normal vascular function [23, 27, 64-66].

A fundamental question regarding the toxicity of AgNP is whether or not differences in particle number or mass dosing influences our toxicological end points. Given the different sizes of AgNP but an equivalent mass delivered in these studies it is reasonable to assume that there are higher numbers of particles in a fixed $200 \mu \mathrm{L}$ sample of $20 \mathrm{~nm}$ AgNP than $110 \mathrm{~nm}$ AgNP. However, we demonstrated that there is no significant difference in I/R injury $24 \mathrm{~h}$ following IT instillation of all AgNP thus at $24 \mathrm{~h}$ it seems that particle number may not be strongly associated with the extent of I/R injury. Furthermore, 7 days following IT exposure a differential response is seen between the citrate and PVP capped AgNP of the same size, suggestive of influence of capping agent on the cardiac I/R injury response and not presumed differences in particle number. It is possible that the cardiac I/R endpoint may simply be insensitive 


\section{Citrate Capped AgNP}

A Normalized Coronary Relaxation Response

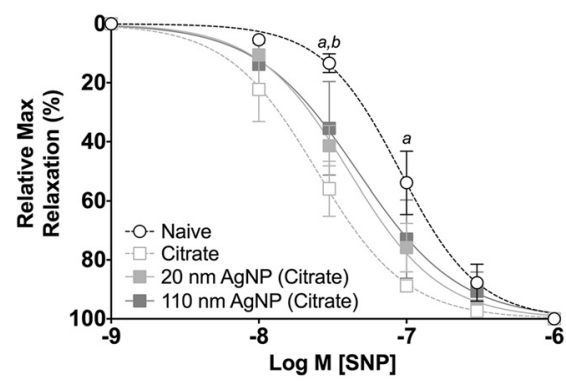

C Normalized Aortic Relaxation Response

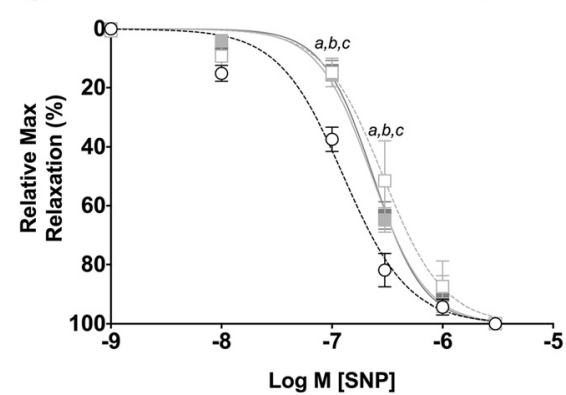

PVP Capped AgNP

B Normalized Coronary Relaxation Response

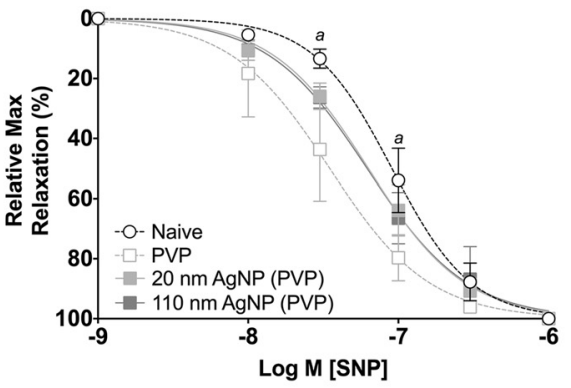

D Normalized Aortic Relaxation Response

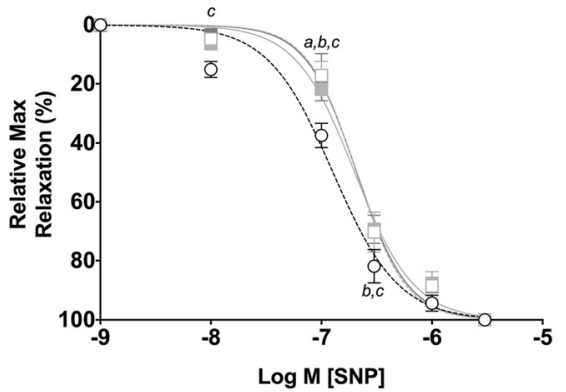

Fig. 10 Isolated Vessel Myography SNP Responses 7 Days post Exposure. Graphs presenting the normalized stress responses of aorta and coronary artery segments 7 days following IT exposure including: coronary responses to citrate capped AgNP (a) coronary responses to PVP capped AgNP (b) aortic responses to citrate capped AgNP (c) and aortic responses to PVP capped AgNP (d). Statistical significance $(p<0.05)$ between: naïve and vehicle indicated by (a), naïve and $20 \mathrm{~nm}$ AgNP indicated by (b), naïve and $110 \mathrm{~nm}$ AgNP indicated by (c), calculated by two-way ANOVA with Tukey post hoc test. Lines represent the nonliner fit to the mean values. Data are reported as mean \pm SEM with $n=3-4$

to particle number induced toxicity. Results from the cytokine concentrations may indicate that surface area of AgNP along with capping agent play the more prominent roles in inducing cardiovascular toxicity. Particles enveloped by a protein corona which is influenced by capping agent have demonstrated differential granulation influencing potentially modulating cytokine release and in turn evolving immunological responses [61]. The capping agents of AgNP may further modulate the way particles interact with aforementioned biological interfaces leading to increased toxicity [59]. The influence of capping agent on cardiovascular toxicity may result from differences in surface charge, which can impact particle adsorption affinity for cellular surfaces [67] as well as cellular uptake [68]. Additionally, ionic dissolution in vivo may be a source of toxicity, although dissolution rate of silver was not measured in this study in vitro studies have examined the contribution of ion dissolution to overall toxicology $[29,30]$. We have previously investigated the role of silver ion and found that within a range of ionic dissolution congruent with in vitro studies, it is unlikely that free silver ions play a large role in the cardiovascular toxicity observed in this current study [27]. The contribution of the species of silver nanomaterial to cardiovascular injury has yet to be fully evaluated, despite pure silver core species being capable of inducing expansion of cardiac ischemiareperfusion injury [27] the magnitude of the injury was less than reported herewith gold core silver particles, raising questions of core stability contributing to in vivo ion dissolution or particle charge.

Although it does not appear citrate or PVP capped $110 \mathrm{~nm}$ AgNP has a strong influence on systemic inflammatory response or protein oxidation, there is a strong effect on the expansion of $\mathrm{I} / \mathrm{R}$ injury. We suggest that AgNP mediated systemic inflammation is not the only mechanism contributing to expansion of $I / R$ injury. A potential alternative mechanism of AgNP toxicity include induction of vascular dysfunction [20,37,69] which leads to an expansion of I/R injury following IT exposure to AgNP.

\section{Conclusions}

The ubiquitous use of engineered nanomaterials makes understanding the potential toxicological outcomes of exposure to such materials a chief public health concern. We investigated the unique cardiovascular toxicity associated with pulmonary exposure to AgNP. In order to evaluate the cardiovascular toxicity endpoints following pulmonary instillation of AgNP we evaluated vascular responses in the aorta and coronary artery, as well as investigated the impact of AgNP on cardiac I/R injury. 


\section{Citrate Capped AgNP 1 Day Post Instillation}

A

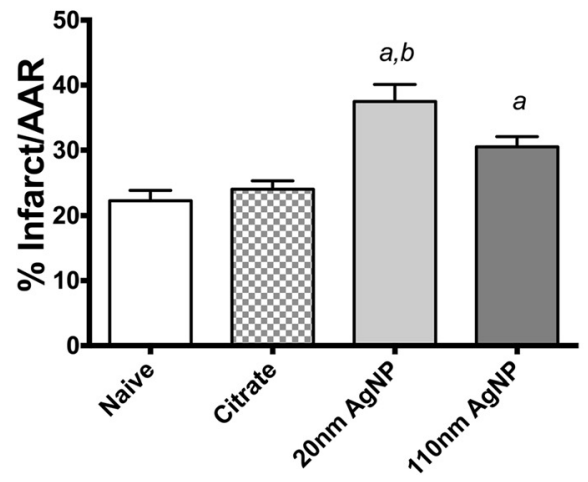

Citrate Capped AgNP

7 Days Post Instillation

C

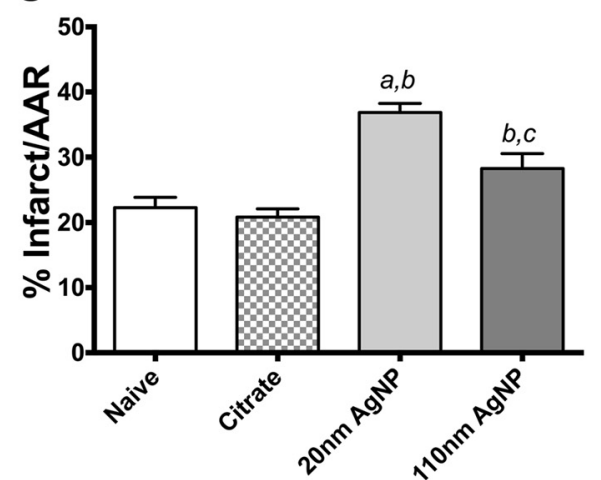

PVP Capped AgNP

1 Day Post Instillation

B

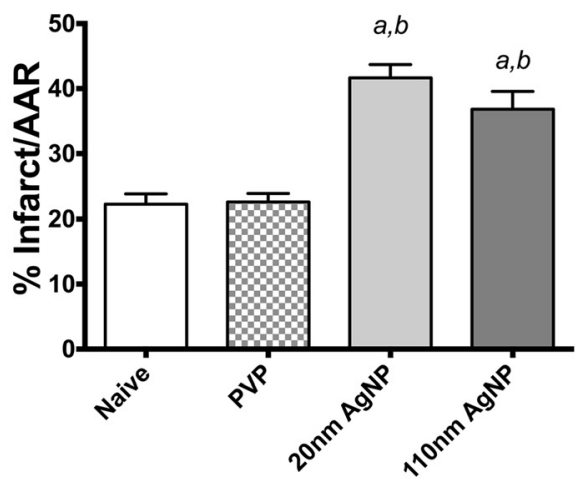

PVP Capped AgNP 7 Days Post Instillation

D

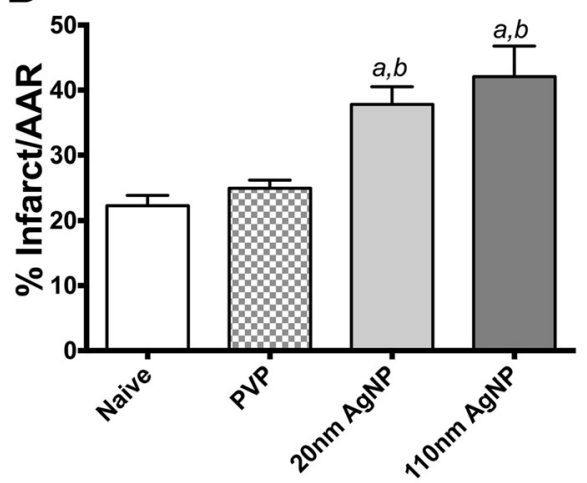

Fig. 11 Cardiac Ischemia/Reperfusion Injury Following IT instillation of AgNP. Graphs of cardiac I/R injury in male SD rats exposed by IT instillation of $200 \mu$ of citrate or PVP vehicle or $200 \mu \mathrm{g}$ AgNP for 1 (panels $\mathbf{a}$ and $\mathbf{b}$ ) or 7 days (panels $\mathbf{c}$ and $\mathbf{d}$ ). Cardiac I/R injury was induced by occlusion of the LAD for 20 min of ischemia and $2 \mathrm{~h}$ of reperfusion. Ischemia-reperfusion injury was expanded 1 day following IT exposure to AgNP compared to vehicle or naive (a). Expansion of I/R injury persists 7 days following IT instillation (b). (a) denotes significance, $(p<0.05)$ calculated by one-way ANOVA with Tukey post hoc test, versus naïve, (b) denotes significant vs vehicle, (c) denotes significant vs capping agent. Data are reported as mean \pm SEM with $n=4$

In an attempt to elucidate mechanisms of AgNP toxicity we also evaluated the serum inflammatory profile, which we hypothesized particle size and capping agents may drive processes leading to expansion of cardiac $\mathrm{I} / \mathrm{R}$ injury. Our data reveals that IT instillation of AgNP results in expansion of cardiac $I / R$ injury 1 day and 7 days post IT when compared to $I / R$ injury from naïve and vehicle controls. Instillation of AgNP did not elicit a strong inflammatory response as measured by circulating serum cytokines, but I/R injury following IT instillation did result in a greater inflammatory response in PVP capped $20 \mathrm{~nm}$ AgNP compared to vehicle controls. The cardiovascular toxicity of AgNP seems to be complex, dependent on several factors including particle size and capping agent. The determination of the persistence of cardiac I/R injury beyond the 7 day time point may be important in understanding the potential public health impact of pulmonary exposures to AgNP.

\section{Additional file}

Additional file 1: Table S1. Mean Serum Concentration of Selected Cytokines Post IT instillation of Citrate Capped AgNP. Table S2. Mean Serum Concentration of Selected Cytokines Post IT instillation of PVP Capped AgNP. (DOCX $27 \mathrm{~kb})$

\section{Acknowledgements}

We would like to thank and acknowledge Josh Volkan, Daniel Becak and Jillian Odom for their technical support with the vascular protocols and BALF cell differentials. We would also like to thank and acknowledge Joshua Morgan for his assistance with the OxyBlot ${ }^{\mathrm{TM}}$ assay. 


\section{Funding}

This work was supported by resources of the National Institute of Environmental Health Sciences U19ES019525, U01ES020127, U19ES019544 and East Carolina University.

\section{Availability of data and materials}

Data supporting the findings are found within the manuscript and supplemental tables. Raw data files will be provided by the corresponding author upon request.

\section{Authors' contributions}

$\mathrm{NAH}$ performed the I/R, OxyBlot ${ }^{\mathrm{TM}}$ assay, and cytokine: experimental design, data analysis, interpretation, and drafted the manuscript. RNU performed I/R experiments, data analysis and interpretation. LCT and AKV performed the vascular experiments, data analysis and interpretation. TRF, RML, and CJW participated in the study design, data interpretation and editing of the manuscript. CJW was responsible for the study design and the coordination of experiments. All authors read and approved of the final manuscript.

\section{Competing interests}

The authors declare that they have no competing interests.

\section{Consent for publication}

Not applicable.

\section{Ethics approval and consent to participate}

East Carolina University's Institutional Animal Care and Use Committee approved all animal handling and experimental procedures. East Carolina University's Institutional Animal Care and Use Committee operates under the accreditation of The animal care and use program at East Carolina University is USDA registered (\#55-R-0010), maintains a PHS Assurance (\#A3469-01), and is fully accredited by AAALAC International (File \#677).

\section{Author details}

'Department of Physiology, Brody School of Medicine at East Carolina University, Greenville, NC 27834, USA. ${ }^{2}$ RTI International, Discovery Sciences, Research Triangle Park, NC 27709, USA.

\section{Received: 1 March 2016 Accepted: 16 August 2016}

Published online: 24 August 2016

\section{References}

1. Nemmar A, Holme JA, Rosas I, Schwarze PE, Alfaro-Moreno E. Recent advances in particulate matter and nanoparticle toxicology: a review of the in vivo and in vitro studies. BioMed research international. 2013;2013:279371. doi:10.1155/2013/279371.

2. Oberdorster G, Oberdorster E, Oberdorster J. Nanotoxicology: an emerging discipline evolving from studies of ultrafine particles. Environ Health Perspect. 2005;113(7):823-39.

3. McShan D, Ray PC, Yu H. Molecular toxicity mechanism of nanosilver. J Food Drug Anal. 2014;22(1):116-27. doi:10.1016/j.jfda.2014.01.010.

4. Kumar V, Jolivalt C, Pulpytel J, Jafari R, Arefi-Khonsari F. Development of silver nanoparticle loaded antibacterial polymer mesh using plasma polymerization process. J Biomed Mater Res A. 2013;101(4):1121-32. doi:10.1002/jbm.a.34419.

5. Mijnendonckx K, Leys N, Mahillon J, Silver S, Van Houdt R. Antimicrobial silver: uses, toxicity and potential for resistance. Biometals: an international journal on the role of metal ions in biology, biochemistry, and medicine. 2013;26(4):609-21. doi:10.1007/s10534-013-9645-z.

6. Quadros ME, Marr LC. Environmental and human health risks of aerosolized silver nanoparticles. J Air Waste Manage Assoc. 2010;60(7):770-81.

7. Hadrup N, Lam HR. Oral toxicity of silver ions, silver nanoparticles and colloidal silver-a review. Regul Toxicol Pharmacol. 2014;68(1):1-7. doi:10.1016/j.yrtph.2013.11.002.

8. Munger MA, Radwanski P, Hadlock GC, Stoddard G, Shaaban A, Falconer J, et al. In vivo human time-exposure study of orally dosed commercial silver nanoparticles. Nanomed: Nanotechnol Biol Med. 2014;10(1):1-9. doi:10.1016/j. nano.2013.06.010

9. Braakhuis HM, Gosens I, Krystek P, Boere JA Cassee FR, Fokkens PH, et al. Particle size dependent deposition and pulmonary inflammation after short- term inhalation of silver nanoparticles. Part Fibre Toxicol. 2014;11:49 doi:10.1186/s12989-014-0049-1.

10. Warheit DB, Donner EM. Risk assessment strategies for nanoscale and fine-sized titanium dioxide particles: Recognizing hazard and exposure issues. Food Chem Toxicol. 2015;85:138-47. doi:10.1016/j.fct.2015.07.001.

11. Silva RM, Anderson DS, Franzi LM, Peake JL, Edwards PC, Van Winkle LS, et al. Pulmonary effects of silver nanoparticle size, coating, and dose over time upon intratracheal instillation. Toxicol Sci. 2015;144(1):151-62. doi:10.1093/toxsci/kfu265.

12. Seiffert J, Hussain F, Wiegman C, Li F, Bey L, Baker W, et al. Pulmonary toxicity of instilled silver nanoparticles: influence of size, coating and rat strain. PLoS One. 2015;10(3), e0119726. doi:10.1371/journal.pone.0119726.

13. Kwon JT, Minai-Tehrani A, Hwang SK, Kim JE, Shin JY, Yu KN, et al. Acute pulmonary toxicity and body distribution of inhaled metallic silver nanoparticles. Toxicol Res. 2012;28(1):25-31. doi:10.5487/TR.2012.28.1.025.

14. Anderson DS, Patchin ES, Silva RM, Uyeminami DL, Sharmah A, Guo T, et al. Influence of particle size on persistence and clearance of aerosolized silver nanoparticles in the rat lung. Toxicol Sci. 2015;144(2):366-81. doi:10.1093/ toxsci/kfv005.

15. Botelho DJ, Leo BF, Massa CB, Sarkar S, Tetley TD, Chung KF et al. Low-dose AgNPs reduce lung mechanical function and innate immune defense in the absence of cellular toxicity. Nanotoxicology. 2015:1-10. doi:10.3109/ 17435390.2015 .1038330

16. Roberts JR, McKinney W, Kan H, Krajnak K, Frazer DG, Thomas TA, et al. Pulmonary and cardiovascular responses of rats to inhalation of silver nanoparticles. J Toxic Environ Health A. 2013;76(11):651-68. doi:10.1080/ 15287394.2013.792024.

17. Martinelli N, Olivieri O, Girelli D. Air particulate matter and cardiovascular disease: a narrative review. Eur J Intern Med. 2013;24(4):295-302. doi:10.1016/j.ejim.2013.04.001.

18. Brook RD. Cardiovascular effects of air pollution. Clin Sci. 2008;115(6):175-87 doi:10.1042/CS20070444

19. Gray DL, Wallace LA, Brinkman MC, Buehler SS, La Londe C. Respiratory and cardiovascular effects of metals in ambient particulate matter: a critical review. Rev Environ Contam Toxicol. 2015;234:135-203. doi:10.1007/978-3319-10638-0_3.

20. Nelin TD, Joseph AM, Gorr MW, Wold LE. Direct and indirect effects of particulate matter on the cardiovascular system. Toxicol Lett. 2012;208(3):293-9. doi:10.1016/j.toxlet.2011.11.008

21. Gorr MW, Youtz DJ, Eichenseer CM, Smith KE, Nelin TD, Cormet-Boyaka E, et al. In vitro particulate matter exposure causes direct and lung-mediated indirect effects on cardiomyocyte function. Am J Phys Heart Circ Phys. 2015;309(1):H53-62. doi:10.1152/ajpheart.00162.2015.

22. Lippmann M. Toxicological and epidemiological studies of cardiovascular effects of ambient air fine particulate matter (PM2.5) and its chemical components: coherence and public health implications. Crit Rev Toxicol. 2014:44(4):299-347. doi:10.3109/10408444.2013.861796.

23. Thompson LC, Urankar RN, Holland NA, Vidanapathirana AK, Pitzer JE, Han L, et al. C (6) (0) exposure augments cardiac ischemia/reperfusion injury and coronary artery contraction in Sprague Dawley rats. Toxicol Sci. 2014:138(2):365-78, doi:10.1093/toxsci/kfu008.

24. Urankar RN, Lust RM, Mann E, Katwa P, Wang X, Podila R, et al. Expansion of cardiac ischemia/reperfusion injury after instillation of three forms of multiwalled carbon nanotubes. Part Fibre Toxicol. 2012;9:38. doi:10.1186/17438977-9-38.

25. Stapleton PA, Abukabda AB, Hardy SL, Nurkiewicz TR. Xenobiotic pulmonary exposure and systemic cardiovascular response via neurological links. Am J Phys Heart Circ Phys. 2015;309(10):H1609-20. doi:10.1152/ajpheart.00546.2015.

26. Minarchick VC, Stapleton PA, Porter DW, Wolfarth MG, Ciftyurek E, Barger M, et al. Pulmonary cerium dioxide nanoparticle exposure differentially impairs coronary and mesenteric arteriolar reactivity. Cardiovasc Toxicol. 2013:13(4):323-37. doi:10.1007/s12012-013-9213-3.

27. Holland N, Becak D, Jonathan HS, Brown J, Carratt S, Winkle L et al. Cardiac Ischemia Reperfusion Injury Following Instillation of $20 \mathrm{~nm}$ Citrate-capped Nanosilver. Journal of Nanomedicine \& Nanotechnology. 2015;2015. doi:10.4172/2157-7439.S6-006.

28. Park J, Lim DH, Lim HJ, Kwon T, Choi JS, Jeong S, et al. Size dependent macrophage responses and toxicological effects of Ag nanoparticles. Chem Commun. 2011:47(15):4382-4. doi:10.1039/c1cc10357a.

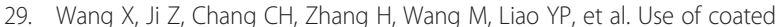
silver nanoparticles to understand the relationship of particle dissolution 
and bioavailability to cell and lung toxicological potential. Small. 2014;10(2):385-98. doi:10.1002/smll.201301597.

30. Munusamy P, Wang C, Engelhard MH, Baer DR, Smith JN, Liu C, et al. Comparison of $20 \mathrm{~nm}$ silver nanoparticles synthesized with and without a gold core: Structure, dissolution in cell culture media, and biological impact on macrophages. Biointerphases. 2015;10(3):031003. doi:10.1116/1.4926547.

31. Drake PL, Hazelwood KJ. Exposure-related health effects of silver and silver compounds: a review. Ann Occup Hyg. 2005;49(7):575-85. doi:10.1093/ annhyg/mei019.

32. Gardner DE. Target organ toxicology series. 4th ed. Boca Raton: CRC/Taylor \& Francis; 2006

33. Katwa P, Wang X, Urankar RN, Podila R, Hilderbrand SC, Fick RB, et al. A carbon nanotube toxicity paradigm driven by mast cells and the IL-(3) (3)/ST (2) axis. Small. 2012;8(18):2904-12. doi:10.1002/smll.201200873.

34. Thompson LC, Frasier CR, Sloan RC, Mann EE, Harrison BS, Brown JM, et al. Pulmonary instillation of multi-walled carbon nanotubes promotes coronary vasoconstriction and exacerbates injury in isolated hearts. Nanotoxicology. 2014;8(1):38-49. doi:10.3109/17435390.2012.744858.

35. Ferrera R, Benhabbouche S, Bopassa JC, Li B, Ovize M. One hour reperfusion is enough to assess function and infarct size with TTC staining in Langendorff rat model. Cardiovasc Drugs Ther. 2009;23(4):327-31. doi:10.1007/s10557-009-6176-5.

36. Haberl N, Hirn S, Wenk A, Diendorf J, Epple M, Johnston BD, et al. Cytotoxic and proinflammatory effects of PVP-coated silver nanoparticles after intratracheal instillation in rats. Beilstein J Nanotechnol. 2013;4:933-40. doi:10.3762/bjnano.4.105.

37. Brook RD, Bard RL, Morishita M, Dvonch JT, Wang L, Yang HY, et al. Hemodynamic, autonomic, and vascular effects of exposure to coarse particulate matter air pollution from a rural location. Environ Health Perspect. 2014;122(6):624-30. doi:10.1289/ehp.1306595.

38. Mann EE, Thompson LC, Shannahan JH, Wingard CJ. Changes in cardiopulmonary function induced by nanoparticles. WileyInterdiscipRevNanomedNanobiotechnol. 2012;4(6):691-702.

39. Miethling-Graff R, Rumpker R, Richter M, Verano-Braga T, Kjeldsen F, Brewer J, et al. Exposure to silver nanoparticles induces size- and dose-dependent oxidative stress and cytotoxicity in human colon carcinoma cells. Toxicol In Vitro. 2014;28(7):1280-9. doi:10.1016/j.tiv.2014.06.005.

40. Shi J, Sun $X$, Lin Y, Zou X, Li Z, Liao Y, et al. Endothelial cell injury and dysfunction induced by silver nanoparticles through oxidative stress via IKK NF-kappaB pathways. Biomaterials. 2014;35(24):6657-66. doi:10.1016/j. biomaterials.2014.04.093.

41. Singh RP, Ramarao P. Cellular uptake, intracellular trafficking and cytotoxicity of silver nanoparticles. Toxicol Lett. 2012;213(2):249-59. doi:10.1016/j.toxlet. 2012.07.009.

42. Eom HJ, Choi J. p38 MAPK activation, DNA damage, cell cycle arrest and apoptosis as mechanisms of toxicity of silver nanoparticles in Jurkat T cells. Environ Sci Technol. 2010:44(21):8337-42. doi:10.1021/es1020668.

43. Cortese-Krott MM, Munchow M, Pirev E, Hessner F, Bozkurt A, Uciechowski P, et al. Silver ions induce oxidative stress and intracellular zinc release in human skin fibroblasts. Free Radic Biol Med. 2009;47(11):1570-7. doi:10. 1016/j.freeradbiomed.2009.08.023.

44. Deten A, Volz HC, Briest W, Zimmer HG. Cardiac cytokine expression is upregulated in the acute phase after myocardial infarction. Experimental studies in rats. Cardiovasc Res. 2002;55(2):329-40.

45. Gabriel AS, Martinsson A, Wretlind B, Ahnve S. IL-6 levels in acute and post myocardial infarction: their relation to CRP levels, infarction size, left ventricular systolic function, and heart failure. Eur J Intern Med. 2004;15(8):523-8. doi:10.1016/j.ejim.2004.07.013.

46. Pomerantz BJ, Reznikov LL, Harken AH, Dinarello CA. Inhibition of caspase 1 reduces human myocardial ischemic dysfunction via inhibition of IL-18 and IL1 beta. Proc Natl Acad Sci U S A. 2001;98(5):2871-6. doi:10.1073/pnas.041611398.

47. Kuznetsova T, Haddad F, Knez J, Rosenberg-Hasson Y, Sung J, Cauwenberghs $\mathrm{N}$ et al. Cytokines profile in hypertensive patients with left ventricular remodeling and dysfunction. Journal of the American Society of Hypertension : JASH. 2015. doi:10.1016/j.jash.2015.10.003.

48. Hoyne GF. Mechanisms that regulate peripheral immune responses to control organ-specific autoimmunity. Clin Dev Immunol. 2011;2011:294968. doi:10.1155/2011/294968

49. Ju ST, Sharma R, Gaskin F, Fu SM. IL-2 controls trafficking receptor gene expression and Th2 response for skin and lung inflammation. Clin Immunol. 2012;145(1):82-8. doi:10.1016/j.clim.2012.07.015.
50. Milic M, Leitinger G, Pavicic I, Zebic Avdicevic M, Dobrovic S, Goessler W et al. Cellular uptake and toxicity effects of silver nanoparticles in mammalian kidney cells. Journal of applied toxicology : JAT. 2014. doi:10.1002/jat.3081.

51. Zhang H, Wang X, Wang M, Li L, Chang CH, Ji Z, et al. Mammalian Cells Exhibit a Range of Sensitivities to Silver Nanoparticles that are Partially Explicable by Variations in Antioxidant Defense and Metallothionein Expression. Small. 2015;11(31):3797-805. doi:10.1002/smll.201500251.

52. Inoue K, Takano H, Koike E, Yanagisawa R, Sakurai M, Tasaka S, et al. Effects of pulmonary exposure to carbon nanotubes on lung and systemic inflammation with coagulatory disturbance induced by lipopolysaccharide in mice. Exp Biol Med. 2008;233(12):1583-90. doi:10.3181/0805-RM-179.

53. Hazarika S, Van Scott MR, Lust RM, Wingard CJ. Pulmonary allergic reactions impair systemic vascular relaxation in ragweed sensitive mice. Vascul Pharmacol. 2010;53(5-6):258-63. doi:10.1016/j.vph.2010.09.005.

54. Huk A, Izak-Nau E, Reidy B, Boyles M, Duschl A, Lynch I, et al. Is the toxic potential of nanosilver dependent on its size? Part Fibre Toxicol. 2014;1 1:65. doi:10.1186/s12989-014-0065-1.

55. Shannahan JH, Podila R, Aldossari AA, Emerson $H$, Powell BA, Ke PC, et al. Formation of a Protein Corona on Silver Nanoparticles Mediates Cellular Toxicity via Scavenger Receptors. Toxicol Sci. 2015;143(1):136-46. doi:10. 1093/toxsci/kfu217.

56. Radauer-Preiml I, Andosch A, Hawranek T, Luetz-Meindl U, Wiederstein M, Horejs-Hoeck J, et al. Nanoparticle-allergen interactions mediate human allergic responses: protein corona characterization and cellular responses. Part Fibre Toxicol. 2016;13(1):3. doi:10.1186/s12989-016-0113-0.

57. Kumar A, Bicer EM, Morgan AB, Pfeffer PE, Monopoli M, Dawson KA et al. Enrichment of immunoregulatory proteins in the biomolecular corona of nanoparticles within human respiratory tract lining fluid. Nanomedicine : nanotechnology, biology, and medicine. 2016. doi:10.1016/j.nano.2015.12.369.

58. Corbo C, Molinaro R, Parodi A, Toledano Furman NE, Salvatore F, Tasciotti E. The impact of nanoparticle protein corona on cytotoxicity, immunotoxicity and target drug delivery. Nanomedicine. 2016;11(1):81-100. doi:10.2217/ nnm.15.188.

59. Das S, Debnath N, Mitra S, Datta A, Goswami A. Comparative analysis of stability and toxicity profile of three differently capped gold nanoparticles for biomedical usage. Biometals: an international journal on the role of metal ions in biology, biochemistry, and medicine. 2012;25(5):1009-22. doi:10.1007/s10534-012-9567-1.

60. Aldossari AA, Shannahan JH, Podila R, Brown JM. Influence of physicochemical properties of silver nanoparticles on mast cell activation and degranulation. Toxicol In Vitro. 2015;29(1):195-203. doi:10.1016/j.tiv. 2014.10.008.

61. Shannahan JH, Podila R, Brown JM. A hyperspectral and toxicological analysis of protein corona impact on silver nanoparticle properties, intracellular modifications, and macrophage activation. Int J Nanomedicine. 2015;10:6509-21. doi:10.2147/JN.S92570.

62. Vesterdal LK, Mikkelsen L, Folkmann JK, Sheykhzade M, Cao Y, Roursgaard M, et al. Carbon black nanoparticles and vascular dysfunction in cultured endothelial cells and artery segments. Toxicol Lett. 2012;214(1):19-26. doi:10.1016/j.toxlet.2012.07.022.

63. Rosas-Hernandez H, Jimenez-Badillo S, Martinez-Cuevas PP, Gracia-Espino E, Terrones $\mathrm{H}$, Terrones $\mathrm{M}$, et al. Effects of 45 -nm silver nanoparticles on coronary endothelial cells and isolated rat aortic rings. Toxicol Lett. 2009;191(2-3):305-13. doi:10.1016/j.toxlet.2009.09.014.

64. Vidanapathirana AK, Thompson LC, Mann EE, Odom JT, Holland NA, Sumner SJ, et al. PVP formulated fullerene (C60) increases Rho-kinase dependent vascular tissue contractility in pregnant Sprague Dawley rats. Reprod Toxicol. 2014:49C:86-100. doi:10.1016/j.reprotox.2014.07.074.

65. Vidanapathirana AK, Thompson LC, Odom J, Holland NA, Sumner SJ, Fennell TR et al. Vascular Tissue Contractility Changes Following Late Gestational Exposure to Multi-Walled Carbon Nanotubes or their Dispersing Vehicle in Sprague Dawley Rats. Journal of Nanomedicine \& Nanotechnology. 2014;5 (3). doi:10.4172/2157-7439.1000201.

66. Gonzalez C, Rosas-Hernandez H, Ramirez-Lee MA, Salazar-Garcia S, Ali SF. Role of silver nanoparticles (AgNPs) on the cardiovascular system. Arch Toxicol. 2014. doi:10.1007/s00204-014-1447-8.

67. Xiong Y, Brunson M, Huh J, Huang A, Coster A, Wendt K, et al. The role of surface chemistry on the toxicity of ag nanoparticles. Small. 2013;9(15):2628-38. doi:10.1002/smll.201202476. 
68. Giri S, Trewyn BG, Lin VS. Mesoporous silica nanomaterial-based biotechnological and biomedical delivery systems. Nanomedicine (Lond). 2007;2(1):99-111. doi:10.2217/17435889.2.1.99.

69. Campen M, Robertson S, Lund A, Lucero J, McDonald J. Engine exhaust particulate and gas phase contributions to vascular toxicity. Inhal Toxicol. 2014;26(6):353-60. doi:10.3109/08958378.2014.897776.

Submit your next manuscript to BioMed Central and we will help you at every step:

- We accept pre-submission inquiries

- Our selector tool helps you to find the most relevant journal

- We provide round the clock customer support

- Convenient online submission

- Thorough peer review

- Inclusion in PubMed and all major indexing services

- Maximum visibility for your research

Submit your manuscript at www.biomedcentral.com/submit 